\title{
DEVELOPMENT OF CARBON EMISSIONS TRADING IN CANADA
}

\author{
JOHN C. GOETZ, ${ }^{*}$ MORELla M. DE CASTRO, ${ }^{* *}$ \\ GRAY TAYLOR, ${ }^{* * *}$ AND KAREN HAUGEN-KOZYRA ${ }^{* * * *}$
}

Given the widely accepted belief that climate change is a real and imminent global threat, regulation of greenhouse gas emissions has grown and will continue to develop both in Canada and internationally. The United Nations Framework Convention on Climate Change and the Kyoto Protocol to the United Nations Framework Convention on Climate Change have the objective of attempting to stabilize greenhouse gas emissions at a level that will prevent damage to the earth by limiting humaninduced emissions.

This article canvasses Alberta's current greenhouse gas emissions regulatory framework and Canada's proposed regulatory framework for air emissions and considers the potential for harmonization of the federal and provincial systems.

Finally, this article explores carbon emissions trading globally, including the voluntary trading market, and considers the future development of carbon emissions trading both in Canada and across the globe.
Compte tenu du fait que le changement climatique représente une menace mondiale réelle et imminente, la réglementation des émissions de gaz est devenue plus importante et continuera de prendre de l'importance autant au Canada qu'à l'échelle internationale. La Convention-cadre des Nations Unies sur les changements climatiques et le Protocole de Kyoto à la Convention-cadre des Nations Unies sur les changements climatiques ont pour but d'essayer de stabiliser les émissions à effet de serre à un niveau qui évitera de causer des dommages à la planète en limitant les émissions causées par les humains.

Cet article examine la convention-cadre actuelle des émissions de gaz à effet de serre de l'Alberta et le projet de convention-cadre réglementaire du Canada pour les émissions dans l'atmosphère et étudie l'harmonisation éventuelle des systèmes fédéral et provincial.

Enfin, l'article explore l'échange de droits d'émission de carbone à l'échelle mondiale, incluant le marché d'échange volontaire et examine le développement futur de l'échange des émissions de carbone autant au Canada que dans le monde entier.

\section{TABLE OF CONTENTS}

I. INTRODUCTION: OVERVIEW OF THE HISTORY BEHIND CLIMATE

CHANGE AND DEVELOPED COUNTRIES’ INITIATIVES TO REDUCE

THE EFFECTS OF GREENHOUSE GASES . . . . . . . . . . . . . . . . . . 378

A. Greenhouse Gases And Their EfFect on
Climate Change $\ldots \ldots \ldots \ldots \ldots \ldots \ldots \ldots \ldots \ldots \ldots \ldots \ldots \ldots \ldots \ldots \ldots \ldots \ldots \ldots \ldots \ldots \ldots$

B. EMISSIONS TRADING THEORY $\ldots \ldots \ldots \ldots \ldots \ldots \ldots \ldots \ldots \ldots$

C. UNITED NATIONS FRAMEWORK CONVENTION ON

CLIMATE CHANGE AND THE KYOTO PROTOCOL . . . . . . . . . . 383

II. ALBERTA’s GREENHOUSE GAS EMISSIONS

REGULATORY FRAMEWORK . . . . . . . . . . . . . . . . . 390

A. Climate Change and EMissions MANAGEMENT ACT . . . . . . . . . 394

B. SPECIFIED GAS EMITTERS REGULATION . . . . . . . . . . . . . . . 395

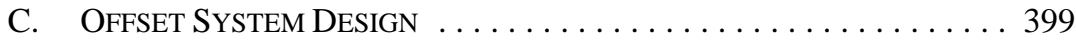

* $\quad$ Associate, Burnet, Duckworth \& Palmer LLP, Calgary, Alberta.

*** Associate, Burnet, Duckworth \& Palmer LLP, Calgary, Alberta.

*** $\quad$ Partner, Bennett Jones LLP, Toronto, Ontario.

**** Acting Director, Policy Development and Offsets Solution Team, Calgary, Alberta. The authors would like to acknowledge the able assistance of Aaron Rogers, articling student at Burnet, Duckworth \& Palmer LLP, and Geoffrey White, associate at Bennett Jones LLP. 
D. Protocols . . . . . . . . . . . . . . . . . . . . . . . . . . 402

III. CANADA's PROPOSED REGULATORY FRAMEWORK

FOR AIR EMISSIONS . . . . . . . . . . . . . . . . . . . . . . . 404

A. Bill C-30: Canada's Clean AIR ACT . . . . . . . . . . . . . . . . 404

B. FEDERAL REgUlAtORY FrAmEWORK ON Air EMissions . . . . . . . 404

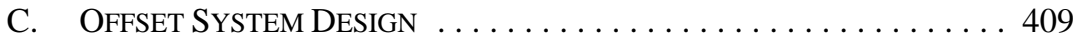

D. POTENTIAL FOR HARMONIZATION OF FEDERAL

AND PROVINCIAL SYSTEMS $\ldots \ldots \ldots \ldots \ldots \ldots \ldots \ldots \ldots . \ldots . \ldots 41$

IV. CARBON EMISSIONS TRADING GLOBALLY -

WHAT IS BEING DONE? . . . . . . . . . . . . . . . . . . . . . . . . . . 412

A. Куото РROTOCOL . . . . . . . . . . . . . . . . . 413

B. InTERNATIONAL EMISSIONS TRAding ASSOCIATION . . . . . . . . . . 414

C. EUROPEAN UNION EMISSIONS TRADING SCHEME . . . . . . . . . . . 414

D. UnITED STATES . . . . . . . . . . . . . . . . . . . . . . . . . . . . . 415

E. WHAT CAN CANADA LEARN FROM THE EUROPEAN UNION

EXPERIENCE AND THE UNITED STATES MODELS? . . . . . . . . . . . . . 418

V. The Voluntary - UnREgUlated MARKet . . . . . . . . . . . . 418

A. PRE-KYOTO PROTOCOL EXPERIENCE IN CANADA . . . . . . . . . . 418

B. Voluntary Market Growth Since

THE KYOTO PROTOCOL . . . . . . . . . . . . . . . . . . . . . . . . . . 419

C. IMPORTANCE OF STANDARDS $\ldots \ldots \ldots \ldots \ldots \ldots \ldots \ldots \ldots \ldots 420$

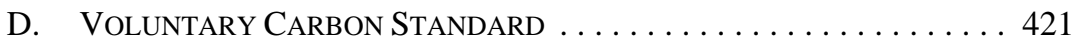

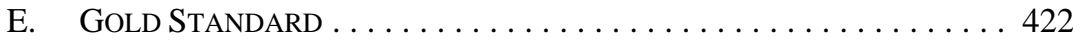

F. INTERNATIONAL ORGANIZATION FOR

STANDARDIZATION $14064 \ldots \ldots \ldots \ldots \ldots \ldots \ldots \ldots$. . . . . . . . 423

G. Future of VoluntARY TRADing $\ldots \ldots \ldots \ldots \ldots \ldots \ldots \ldots . \ldots 423$

H. Where Regulated MARKETS Do Not Exist . . . . . . . . . . . . . 423

I. BRIDGING DIFFERING STANDARDS . . . . . . . . . . . . . 424

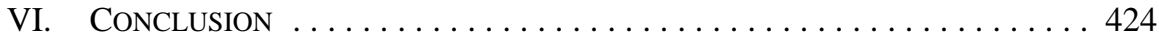

\section{INTRODUCTION: OVERVIEW OF THE HISTORY BEHIND \\ Climate ChANGE AND DEVELOPED COUNTRIES’ INITIATIVES TO REDUCE THE EFFECTS OF GREENHOUSE GASES}

We shall require a substantially new manner of thinking if mankind is to survive.

— Albert Einstein

When Einstein spoke these words, he was referring to the impact that humans were having on the earth. After two decades of intense study and widespread debate, the scientific community appears to be ready to adopt a similar view. Scientists have reached consensus that climate change is not only a real problem with potentially catastrophic consequences, but that it is being caused by human activity: specifically, the emission of increasing amounts of greenhouse gases (GHGs). 
The United Nations, through its United Nations Framework Convention on Climate Change, ${ }^{1}$ and governments around the world have now accepted climate change and its potential consequences as a matter of fact and are scrambling to implement policies and regulations to address it.

\section{A. Greenhouse GASES AND Their EFFEct On Climate CHANGE}

The earth's climate is powered by the sun, which radiates energy onto the earth. Part of this energy is absorbed by the earth's surface and atmosphere, and the energy is in turn, radiated back to space by the earth. Throughout this process, heat continues to be exchanged between the earth's surface and the atmosphere. The earth's temperature is controlled by the thin layer of GHGs found in the atmosphere. GHGs are those essential gases, "both natural and anthropogenic that absorb and re-emit infrared radiation."2 The "thickening" of the layer of GHGs has an effect on the earth's climate exhibited through a warming of the earth's atmosphere, ultimately creating what has been coined the "greenhouse effect."

The concentration levels of GHGs in the earth's atmosphere have increased since 1750 as a result of certain human activities, including the burning of coal and fossil fuels, and land usage and practices. ${ }^{3}$ The increase of these GHG levels has resulted in the world's surface temperature rising approximately 0.74 degrees Celsius from 1906 to 2005, with 11 of the 12 years from 1995 to 2006 being the warmest on record since 1850, the year in which instrumental record-keeping of surface temperatures commenced. ${ }^{4}$ Although the temperature increase may appear to be insignificant, the resultant trend is not. The current concentrations of GHGs have reached 380 parts per million of carbon dioxide equivalent $\left(\mathrm{CO}_{2} \mathrm{e}\right),{ }^{5}$ which exceeds the natural range of GHGs over the last 650,000 years. ${ }^{6}$ If the trend continues, it has been suggested that the earth's surface temperature will increase an average of five degrees Celsius during the twenty-first century, which could trigger reversals in human

9 May 1992, 1771 U.N.T.S. 107, 31 I.L.M. 849 (entered into force 21 March 1994) [UNFCCC]. Ibid., art. 1. See also Intergovernmental Panel on Climate Change (IPCC), Climate Change 2007: The Physical Science Basis (Cambridge, U.K.: Cambridge University Press, 2007). Nitrogen (78 percent) and oxygen (21 percent) are the predominant gases in the atmosphere; however, they do not influence the greenhouse effect (at 97,115$)$. The greenhouse effect is mainly influenced by water vapour and carbon dioxide $\left(\mathrm{CO}_{2}\right)$ (at 115); also contributing to it are "methane, nitrous oxide, ozone and several other gases that are present in smaller amounts" (at 115).

$3 \quad$ Ibid. at 2.

$4 \quad$ Core Writing Team, Rajendra K. Pachaui \& Andy Reisinger, eds., Climate Change 2007: Synthesis Report (Geneva: Intergovernmental Panel on Climate Change, 2008) at 30.

5 Ibid. at 37. Carbon dioxide equivalent $\left(\mathrm{CO}_{2} \mathrm{e}\right)$ is:

a metric measure used to compare the emissions from various greenhouse gases based upon their global warming potential (GWP). [ $\mathrm{CO}_{2} \mathrm{es}$ ] are commonly expressed as "million metric tonnes of carbon dioxide equivalents (MMTCDE)." The $\left[\mathrm{CO}_{2} \mathrm{e}\right]$ for a gas is derived by multiplying the tonnes of the gas by the associated GWP. MMTCDE = (million metric tonnes of a gas) $\mathrm{x}$ (GWP of the gas). For example, the GWP for methane is 21 and for nitrous oxide 310. This means that emissions of 1 million metric tonnes of methane and nitrous oxide respectively is equivalent to emissions of 21 and 310 million metric tonnes of carbon dioxide.

“Carbon dioxide equivalent," online: European Environment Agency (EEA) <http://www.eea.europa. $\mathrm{eu} />$.

${ }_{6} \quad$ Ibid. at 37, 72. Scientists have been able to determine historical GHG levels through the analysis of ice core samples taken from the Antarctic. 
development. ${ }^{7}$ This temperature increase would be equivalent to the temperature change that resulted in the occurrence of the last ice age. ${ }^{8}$ It has also been suggested that if nothing is done, climate change could have irreversible social and economic effects, including the loss of 5 percent of global gross domestic product (GDP) as a conservative scenario. ${ }^{9}$

Carbon dioxide $\left(\mathrm{CO}_{2}\right)$ is responsible for over 60 percent of the greenhouse effect. Once emitted, $\mathrm{CO}_{2}$ and other GHGs remain in the atmosphere for an extensive period of time. The scientific community has suggested that even if the global community were to take the most drastic measures available in an attempt to mitigate the effect of global warming, mitigation efforts would not become perceptible until the mid-2030s. The burning of coal, oil, and natural gas releases carbon into the atmosphere that has been stored in such fuel sources for millions of years, and as a consequence, upsets the carbon cycle (the system by which carbon is exchanged between the air, the oceans, and vegetation), which contributes to the effects on the earth's climate. The levels of $\mathrm{CO}_{2}$ being released into the atmosphere are rising by more than 10 percent every 20 years, with a notable exception to this rule being that such levels increased by 80 percent between the years 1970 and $2004 .{ }^{10} \mathrm{G} 8$ countries account for 47 percent of global $\mathrm{CO}_{2}$ emissions, ${ }^{11}$ and the aggregate emissions of China and India will soon be amongst the highest. However, currently, the per capita carbon footprint ${ }^{12}$ of the United States (20.6 tonnes of $\left.\mathrm{CO}_{2} \mathrm{e}\right)^{13}$ is five times that of China and more than 15 times that of India. ${ }^{14}$ Canada's per capita carbon footprint is 20 tonnes of $\mathrm{CO}_{2} \mathrm{e} .{ }^{15}$ Canada is responsible for 2 percent of the 29,000 million tonnes of GHGs released into the atmosphere annually, of which 19 percent is attributed to the oil and gas industry (excluding oil sands) and 4 percent is attributed to the oil sands. ${ }^{16}$

By the year 2030, the demand for energy by developed nations is estimated to increase by 60 percent, ${ }^{17}$ and the future investment on energy infrastructure in such nations is expected to exceed US\$20 trillion between 2005 and $2030 .{ }^{18}$ The majority of the energy demand will be satisfied using fossil fuels, which as mentioned above, are significant contributors to the

Ibid. at 49, 64-66. Examples would include the displacement of communities due to either flooding or drought, decrease in harvest yields, or water shortages, just to name a few.

United Nations Development Programme, Human Development Report 2007/2008; Fighting climate change: Human solidarity in a divided world (New York: Palgrave Macmillan, 2007) at 3.

Nicholas Stern, The Economics of Climate Change: The Stern Review (Cambridge, U.K.: Cambridge University Press, 2007) at Xv.

Ibid. at 5, n. 4.

2006 Interim Compliance Report (9 March 2007), online: G8 Information Centre <http://www.g8. utoronto.ca/evaluations/2006compliance_interim/2006_08_interim_climate.pdf>.

Carbon footprint is the measure of the impact human activities and practices have on the environment. The carbon footprint is expressed in $\mathrm{CO}_{2} \mathrm{e}$ : see "What is a Carbon Footprint?" Carbon Footprint Ltd., online: Carbon Footprint Ltd. <http://www.carbonfootprint.com/carbonfootprint.html>.

United Nations Development Programme, supra note 8 at 43.

Ibid.

Ibid.

Alberta's Oil Sands: Opportunity. Balance. (Edmonton: Alberta Environment, 2008) at 9. Note, these percentages are bound to vary depending upon the source.

The National Academies, “Joint science academies' statement: Global response to climate change” (7 June 2005), online: The National Academies <http://www.nationalacademies.org/onpi/06072005.pdf > . Core Writing Team, Pachaui \& Reisinger, supra note 4 [footnotes omitted]. 
increase of $\mathrm{CO}_{2}$ emissions and climate change. Scientists are concerned that if we maintain this trend, we may lock the world's climate into an irreversible trajectory.

\section{B. EMISSIONS TRADING THEORY}

Emissions trading is a market-based regulatory tool that is used to help reduce the costs associated with limiting emissions of GHGs and other gases into the atmosphere. It is a major component of international and domestic climate change policy in respect of GHGs, although it has also been used with apparent success to address the challenge of acid deposition from sulphur dioxide $\left(\mathrm{SO}_{2}\right)$ and nitrogen oxides $\left(\mathrm{NO}_{\mathrm{X}}\right)$.

As an alternative to a command-and-control penalty regime or taxes, regulation of emissions is increasingly taking the form of a "cap-and-trade" system. This involves a government or regulatory agent thereof setting an absolute limit or "cap" for emissions. Allowances representing the right to emit a certain amount are then allocated to certain entities (for example, countries under the Kyoto Protocol to the United Nations Framework Convention on Climate Change ${ }^{19}$ or large industrial polluters within those countries), and the aggregate of all the allowances that the regulator allocates is equal to the cap. Regulated entities are not allowed to have emissions exceeding the amount of allowances given to them and if they do exceed their allowances, they must purchase excess allowances from another entity whose emissions are less than its allowance.

The claimed advantage of emissions trading is that it can, through a mix of regulation and competition, allow for the cost of emission reductions to be allocated efficiently to where the costs will be lowest by forcing emitting entities to determine their marginal cost of abatement and to then consider the most cost-effective way of achieving compliance. This is the case either at the micro (firm) level or at the macro (country) level. To give an example, let us say that Emitter A (a country or company, as applicable) and Emitter B each have allowances to emit a certain amount of a regulated gas, and in relative terms, it is less expensive for Emitter A to reduce its emissions and more costly for Emitter B to reduce its emissions. In this scenario, Emitter A can reduce its emissions below the amount of allowances it has, and sell excess allowances to Emitter B at a price that is profitable (that is, at a price that is more than what it cost to make the reductions), but less expensive to Emitter B than what it would pay if it undertook the reductions on its own. In this example there are the same amount of reductions as would occur in a capped system without trading, but the trading ensures that both parties are economically better off in meeting their targets. As Sonia Labatt and Rodney $\mathrm{R}$. White point out, the theory is simple but the implementation is politically (and legally, we would add) very complex. ${ }^{20}$

20 Sonia Labatt \& Rodney R. White, Carbon Finance: The Financial Implications of Climate Change (Hoboken, N.J.: John Wiley \& Sons, 2007) at 140:“[in] theory, a market works if a set of conditions can be met, such as differentiated abatement costs between participants, transparency of transactions so as to permit price discovery, provision for counterparty risk, and so on. The political problem is to discover how such a market might be started" [emphasis in original]. The authors liken emissions trading through a cap-and-trade regime to forcing a company to make a make-or-by decision with respect to emission reductions, but "[i]n practice, the implementation of these systems is a great deal more complicated than 
An alternative approach to emissions trading, and one currently officially favoured by some in Canada ${ }^{21}$ and the U.S., ${ }^{22}$ is to use intensity targets, meaning that instead of putting an absolute limit on the amount of allowed emissions, a limit is put on the amount of emissions for every unit of economic output (units of production at the micro level and GDP at the macro level). Trading in the context of an emission intensity system generally follows a baseline-and-credit model. Under this model, there is generally no initial allocation of allowances, and the target represents a percentage of the baseline. Credits will only be conferred on a regulated emitter in respect of its performance if it keeps its emissions below its target. Alternatively, there could be an initial allocation of allowances in an intensity-based system by giving each regulated entity allowances equal to its production in past years multiplied by an intensity target. One controversial advantage of using intensity targets is that industry will not be penalized for increasing its production. ${ }^{23}$ However, it is the fact that intensity-based targets do not guarantee any absolute reductions in emissions that renders such targets vulnerable to frequent criticism from environmentalists. Another disadvantage is that companies cannot be rewarded for reducing production or moving it out of the jurisdiction, although techniques also exist in a cap-and-trade context to correct this problem.

Emissions trading systems can also allow for offsets, an increasingly popular mechanism by which credits are created through voluntary action taken by non-regulated entities or by regulated entities in respect of non-regulated activities that result in GHG emission reductions or removals. For example, a regulated entity may be able to meet its target not only by reducing the emissions from its operations to a level equal to or lower than the amount of its allowances, but also by earning or purchasing credits from projects undertaken elsewhere. The central concept in offsetting is additionality, that is, that the reductions are in addition to any that would otherwise occur in the business as usual (BAU) scenario. The concept of additionality "is a central, complicated, and controversial touchstone for project-based emissions trading." 24 Offsetting, despite its popularity, continues to be controversial insofar as there is (1) scientific disagreement over the effectiveness of certain sinks, such as forests, to remove carbon from the atmosphere; (2) skepticism over the ability to accurately certify and monitor emission reductions; and (3) concerns by some that offsetting does nothing to address the consumption patterns linked with the causes of global warming.

\footnotetext{
the theory might suggest” (at 138).

21 Canada's proposed climate change program involves intensity targets: Canada, Turning the Corner: Regulatory Framework for Industrial Greenhouse Gas Emissions (Ottawa: Environment Canada, 2008), online: Environment Canada <http://www.ec.gc.ca/doc/virage-corner/2008-03/pdf/COM541_Framework.pdf> [Regulatory Framework]. "Project Green” under the former government in Canada was also intensity-based.

22 For example, the Bush administration in the United States stated in 2002 that its goal was to reduce emissions per dollar of gross domestic product by 18 percent by 2012: William Pizer, "The Case for Intensity Targets,” (January 2005), online: Resources for the Future <http://www.rff.org/RFF/ Documents/RFF-DP-05-02.pdf>.

$23 \quad$ Ibid. at 7-9.

24 Kyle W. Danish, “The International Regime” in Michael B. Gerrard, ed., Global Climate Change and U.S. Law (Chicago: American Bar Association, 2007) 31 at 45.
} 
The global community has options to mitigate the impact of $\mathrm{CO}_{2}$ emissions on the earth's climate. International agreements and conventions (for example, the Kyoto Protocol and the UNFCCC) have been established in recognition of the problem, which have, in turn, motivated the design of national policies and the creation of an international market for carbon credits. Developed countries, including Canada and the U.S., have commenced with processes of implementing policies and mechanisms with the ultimate purpose of controlling the intensity of the GHG emissions. On 10 March 2008, the Government of Canada released a report entitled Turning the Corner: Regulatory Framework for Industrial Greenhouse Gas Emissions, which outlines the federal government's plan to reduce GHG emissions in Canada by 20 percent by 2020 and by 60 percent to 70 percent by $2050 .^{25}$

\section{UNITED NATIONS FRAMEWORK CONVENTION ON CLIMATE CHANGE AND THE КYOTO PROTOCOL}

\section{Intergovernmental Panel on Climate Change}

The U.N. has been the lead international organization in tackling climate change by bringing the related issues to the international stage and establishing panels and committees geared toward bringing countries together to design mechanisms and policies intended to mitigate the effects of climate change.

In 1988, the World Meteorological Organization (WMO) and the U.N. Environment Programme (UNEP) established the Intergovernmental Panel on Climate Change (IPCC), a global scientific body with a mandate to assist policy-makers around the world by providing objective information on climate change and its real and potential effects. The IPCC's supporters include the membership of the WMO and the UNEP. The IPCC's scientists participate in the preparation, drafting, and reviewing of the IPCC's reports, which include analysis and interpretation of available scientific literature relevant to climate change, resultant risks to the earth's population, and mitigation measures and adaptation options that could be adopted. The IPCC does not conduct independent research or monitor climate change.

The IPCC's reports are intended to be open, transparent, objective, and policy-neutral. The first IPCC Assessment Report, issued in 1990, reflecting the views of approximately 400 scientists from around the world, played a significant role in the development of the UNFCCC. The second IPCC Assessment Report, issued in 1995, was relied upon during the negotiations of the Kyoto Protocol. Subsequent IPCC reports were issued in 2001 and 2007, both of which received the general approval of the international community. ${ }^{26}$

\section{UNITED NATIONS FRAMEWORK CONVENTION ON CLIMATE CHANGE}

In 1992, the U.N. drafted the UNFCCC ${ }^{27}$ an international convention that came into force on 21 March 1994 and has been ratified by 192 countries, including Canada and the U.S. The 
objective of the UNFCCC is to establish a framework for governments to co-operate with each other in addressing climate change. The UNFCCC focuses on the needs of developing countries and the stabilization of GHG emissions within a time frame sufficient to (1) anticipate and allow the natural adaptation to climate changes; and (2) minimize human-induced damage or interference with the climate such as food shortages and other negative impacts on human development. ${ }^{28}$ The burden of addressing climate change is placed primarily on developed nations that are the major sources of GHG emissions. However, the decisions of the UNFCCC are made in association with the Conference of the Parties (COP), the UNFCCC's highest decision-making authority, ${ }^{29}$ with members from both the developed and developing countries.

Depending upon the commitments that are to be borne by each country, the UNFCCC has divided its members into three groups:

(1) Annex I - this group consists of countries that were members of the Organization for Economic Co-Operation and Development (OECD) in 1992, as well as certain countries with economies considered to be Economies in Transition (EIT), such as Russia, the Baltic States, and Central and Eastern European States. Canada is an Annex I party.

(2) Annex II — this group is a sub-group of the Annex I parties, and only includes the countries that were members of the OECD in 1992. This group has the obligation to provide financial resources to EIT and developing countries, in addition to providing assistance with respect to the transfer of environmentally friendly technologies, in order to assist such countries with the reduction of GHGs and to adapt to climate change.

(3) Non-Annex I - this group is comprised mainly of developing countries. Certain groups of countries under Non-Annex I receive different treatment as they are recognized as being particularly vulnerable to the effects of climate change (such as countries that are in low-lying areas or prone to desertification), or to the measures taken by the UNFCCC as a response to climate change (such as countries whose economies are highly dependent on fossil fuels). ${ }^{30}$

Michael B. Gerrard, "Introduction and Overview” in Gerrard, supra note 24, 1 at 1-3.

The UNFCCC has two subsidiary bodies that provide advice to the Conference of the Parties: the Subsidiary Body for Scientific and Technological Advice and the Subsidiary Body for Implementation. The UNFCCC also includes three Constituted Bodies, as follows: (1) the Consultative Group of Experts, which assists in preparing national communications from Non-Annex I parties; (2) the Expert Group of Technology Transfer, which includes 20 experts who provide scientific and technical advice for the development of environmentally friendly technologies; and (3) the Least Developed Countries Expert Group, which assists in the implementation and preparation of national adaptation programs for Least Developed Countries. See "Convention Bodies," online: UNFCCC <http://unfccc.int/essential_ background/convention/convention_bodies/items/2629.php>; "Constituted Bodies under the Convention,” online: UNFCCC <http://unfccc.int/essential_background/convention/convention_ bodies/constituted_bodies/items/2657.php>.

“Parties and Observers," online: UNFCCC <http://unfccc.int/parties_and_observers/items/2704.php>. 
Membership of the UNFCCC also includes certain countries that are considered to be "least developed." These countries are given special consideration by the UNFCCC as a result of their inability to respond to climate change and to adapt to its effects. ${ }^{31}$

All parties to the UNFCCC are obliged to provide the COP with periodic reports of GHG emissions and to develop programs and policies directed towards the reduction of GHG emissions, the mitigation of climate change effects, and the development of technology and processes to be used for those purposes. In addition to the pursuit of these goals, Annex I countries are obligated to provide scientific, technological, technical, and financial support to developing countries, particularly those developing Non-Annex I countries that are expected to experience the most drastic adverse effects of climate change. ${ }^{32}$

\section{KYOTO PROTOCOL}

The Kyoto Protocol was established as a framework for achieving the objectives of the UNFCCC; it was adopted in Kyoto, Japan, in December 1997, and came into force on 16 February 2005. The Marrakesh Accords, adopted by the COP in Montreal, Canada, in 2005, outline the basis for the implementation of the Kyoto Protocol. ${ }^{33}$

The objective of the Kyoto Protocol mirrors the objective of the UNFCCC - the stabilization of GHG emissions at a level that will prevent damage to the climate by reducing human-induced GHG emissions on a global scale to 5 percent below 1990 levels by the year 2012. ${ }^{34}$ For that purpose, the Kyoto Protocol establishes binding emission reduction targets ${ }^{35}$ and timetables for the ratifying countries. The targets are based on emission reductions relative to 1990 levels and vary from minus- 8 percent to plus-10 percent from country to country. ${ }^{36}$ Each country has an allowable emissions level, referred to as the "assigned amount," established in Annex B to the Kyoto Protocol. Each country's target is also outlined in Annex B and the country's GHG emissions during the base year (1990 in the case of Canada) determine the country's commitment for the five-year period from 2008 to 2012: these targets are denominated in assigned amount units (AAUs). ${ }^{37}$

The Kyoto Protocol enables Annex I parties to modify their assigned amount through land use, land-use change, forestry activities, and by participating in certain mechanisms outlined under the Kyoto Protocol, which are explained below. Through these modifications to their assigned amounts, Annex I parties can generate, cancel, acquire, and transfer emission

\footnotetext{
31 Ibid.

32 The UNFCCC, supra note 1, art. 4 makes special mention of countries that meet the following criteria: small islands located in low-lying coastal areas; arid and semi-arid areas; forested areas and areas prone to forest decay; or areas prone to natural disaster, drought, desertification, with high urban air pollution, and fragile ecosystems, amongst others.

33 United Nations Framework Convention on Climate Change, Kyoto Protocol Reference Manual on Accounting of Emissions and Assigned Amounts (Germany: United Nations Framework Convention on Climate Change, 2008), online: UNFCCC < http://unfccc.int/resource/docs/publications/08_unfccc _kp_ref_manual.pdf> [Kyoto Reference Manual] at 12, 20.

Supra note 19, art. 3(1).

Kyoto Reference Manual, supra note 33 at 13.

Ibid.

Ibid.: Assigned amount units are denominated in tonnes of $\mathrm{CO}_{2} \mathrm{e}$.
} 
allowances (also known as carbon credits). The Kyoto Protocol contains a number of flexible mechanisms intended to help reduce the cost and difficulty of compliance, including the Clean Development Mechanism (CDM), Joint Implementation (JI), and emissions trading. Carbon credits earned through these compliance mechanisms may be traded to other Kyoto Protocol participants or banked for future use in meeting emission reduction targets. However, Annex I parties must meet certain eligibility criteria included in the Kyoto Protocol in order to rely on these mechanisms.

\section{Clean DeVelopment Mechanism}

CDM, a project-based mechanism, is outlined in art. 12 of the Kyoto Protocol. ${ }^{38}$ CDM provides Annex I parties (and public and private entities thereof) with the option of funding emission reduction projects for Non-Annex I parties. Such projects must be geared to reducing GHG emissions or encouraging afforestation and reforestation. CDM projects must be certified by the CDM Executive Board and must create verifiable emission reductions or removals, ${ }^{39}$ in addition to any reductions that would have occurred in the BAU scenario. The rationale for the CDM is that it allows Non-Annex I Parties (those parties that do not, as a result of an equitable bargain, have to reduce their aggregate emissions) to participate in the first commitment period while stimulating sustainable development (as determined by the host country's Designated National Authority (DNA)) and allowing Annex I countries to achieve compliance through lower-cost mitigation projects. To be issued Certified Emission Reductions (CERs), a project must be registered by the CDM Executive Board. The CDM project cycle involves five main stages: (1) project design; (2) validation and registration; (3) implementation and monitoring; (4) verification and certification; and (5) issuance of CERs. ${ }^{40}$ Three types of Kyoto Protocol units may be generated through the implementation of such projects: CERs, temporary CERs, and long-term CERs.

In the project design stage, a project's proponent (Project Proponent) must seek approval from the host country's DNA and must complete a Project Design Document which contains information and justification about the project, how the project's baseline emissions will be calculated and monitored (referred to as a methodology but known commonly as a quantification protocol), its actual baseline, how the project will be monitored, additionality, contribution to sustainable development, and proposed crediting period (either one non-renewable ten-year period or one twice-renewable seven-year period). ${ }^{41}$ A Project Proponent must also seek approval of the project by its home country's DNA or another

$38 \quad$ Supra note 19, art. 12.

39 See Kyoto Reference Manual, supra note 33 at 18; “Clean Development Mechanism (CDM),” online: UNFCCC <http://cdm.unfccc.int/>: The parties involved in an emission reduction project must demonstrate to the CDM Executive Board that the reductions or removals achieved through the project on or after January 2000 are in addition to those that would have occurred in the normal course of business in order for the CDM credits to be generated. In the case of projects involving afforestation or reforestation, different rules apply.

$40 \quad$ “CDM Project Activity Cycle,” online: UNFCCC <http://cdm.unfccc.int/Projects/pac/index.html>.

41 Pursuant to Kyoto Protocol, supra note 19, art. 12(5)(a), “[v]oluntary participation approved by each Party involved” is a precondition to certification. Canada’s designated national authority is the Clean Development Mechanism and Joint Implementation Office within the Department of Foreign Affairs and International Trade, and an explanation of the Canadian approval process may be found online: Foreign Affairs and International Trade Canada <http://www.international.gc.ca/cdm-mdp/index.aspx> [FAITC]. 
country's DNA. ${ }^{42}$ In the validation and registration stage, a Designated Operational Entity (DOE) (a company approved by the CDM, of which there are currently $17^{43}$ ) must validate the project, that is, assess whether the project complies with the CDM and will achieve its stated goals. If the Executive Board concurs with the DOE, the Executive Board registers the project. During the implementation and monitoring stage, the Project Proponent must monitor the project in accordance with the approved Project Design Document and must thereafter, in order to receive CERs, submit a monitoring report to the Executive Board wherein the actual emission reductions are calculated. This report must be verified, that is, audited, by a DOE different from the one who validated the Project Design Document. If the Executive Board concurs with the DOEs verification, the Project Proponent will be issued CERs.

The Kyoto Protocol allows CERs obtained during the period from 2000 to the start of the first commitment period (January 2008) to be used to achieve compliance in the first commitment period, although such projects have to have been registered by the end of 2006 . CERs issued during the first commitment period may also of course be used. Under Canada's proposed federal regulatory plan, credits from the CDM can be used to meet up to 10 percent of a firm's total emission reduction obligation. ${ }^{44}$

There are currently 51 large-scale baseline and monitoring methodologies approved by the CDM Executive Board, ranging in relative complexity from fuel switching and other such efficiency projects (for example, leak reduction) to more complex grid-substitution initiatives. ${ }^{45}$ Forestry-related projects under the CDM, and generally in other regimes, are treated differently due to the non-permanence of carbon reductions and the unavoidable threat of reversal (for example, due to forest fires or pests). There are currently nine largescale methodologies approved for afforestation and reforestation projects. ${ }^{46}$ For smaller scale projects, there is a more simplified procedure, and to date, there are 33 approved small-scale methodologies. $^{47}$

\section{JOINT IMPLEMENTATION}

The JI mechanism, as established by art. 6 of the Kyoto Protocol, allows Annex I Parties to invest in projects in other Annex I countries that reduce GHG emissions or enhance sequestration of GHGs compared to a BAU standard on or after 1 January 2008. Through this mechanism, the investor is credited for the emission reductions or removal through receipt

42 Ibid.

43 See "List of DOEs," online: UNFCCC <http://cdm.unfccc.int/DOE/list/index.html>: the following companies are approved by the CDM: Japan Quality Assurance Organization; JACO CDM., LTD.; Det Norske Veritas Certification AS; TÜV SÜD Industrie Service GmbH; Deloitte Tohmatsu Evaluation and Certification Organization; Japan Consulting Institute; Bureau Veritas Certification Holding SAS; SGS United Kingdom Ltd.; The Korea Energy Management Corporation; TÜV Rheinland Japan Ltd.; KPMG Sustainability B.V.; Spanish Association for Standardisation and Certification; TÜV NORD CERT GmbH; Lloyd’s Register Quality Assurance Ltd.; Colombian Institute for Technical Standards and Certification; Korean Foundation for Quality; and RINA S.p.A.

44 Regulatory Framework, supra note 21 at iv.

45 See "Baseline and monitoring methodologies," online: UNFCCC < http://cdm.unfccc.int/methodologies/ index.html>.

46 Ibid.

$47 \quad$ Ibid. 
of Emission Reduction Units (ERUs). Those intending to utilize the JI mechanism must comply with specific requirements, including the accurate reporting of GHG emissions and the establishment of a registry to track such emissions and emission reduction activities. ${ }^{48}$ Countries that have met these requirements may carry out JI projects and receive credits beginning in 2008 although the Kyoto Protocol allows for certain projects that commenced after 1 January 2002 to be registered under the JI mechanism. JI projects are primarily expected to be carried out in EIT. ${ }^{49}$

Both the CDM and the JI mechanisms recognize that it may be more economically efficient for a regulated party to conduct projects in developing countries where costs are generally lower than in its own country. Theoretically, the environmental benefits of the project will be the same in either case. Canada has established the CDM and JI Office as the "designated national authority for approving emission reduction projects with international partners." 50 The office provides the authorizations and approval requirements necessary for industry, non-governmental organizations (NGOs), and governments to participate in CDM and JI projects.

Under the emissions trading rules outlined in art. 17 of the Kyoto Protocol, only Annex I parties may transfer or acquire from another Annex I party reductions that they achieve below their assigned amounts or purchase credits if they emit beyond their assigned amounts. The assigned amount is divisible into the AAUs referred to above, with one AAU being the right to emit one tonne of $\mathrm{CO}_{2} \mathrm{e}$. Under the Kyoto Protocol, AAUs and other project-based credits earned under the other two flexibile mechanisms are added to a Party's assigned amount and any such units are subtracted from the transferring country's assigned amount. Annex I parties are limited as to the number of units that can be exchanged as each Annex I party is obliged to hold a certain number of units in its national Kyoto Protocol unit reserve based on the commitment period of the reserve. The purpose of such a limitation is to prevent Annex I parties from failing to meet their emissions-related commitments. ERUs will not be eligible for use by regulated emitters in Canada's proposed federal regulatory plan, nor is the government planning on purchasing ERUs. This is likely due to the perception that such credits are "hot air" and not representative of real reductions because some countries who had been transitioning to a market economy had collapsed, resulting in actual but otherwise artificial GHG emission reductions of 30 to 40 percent relative to the 1990 Kyoto Protocol baseline. ${ }^{51}$ A related problem was that the artificial oversupply of credits to those countries

48 See Kyoto Reference Manual, supra note 33 at 15, 17: Tracking the emissions reduced or removed under the JI mechanism can be accomplished in two different ways, unimaginatively named "track one” and “track two.” Track one verification allows the project's host to verify its own projects without the need of external review and to issue the resulting emission reduction units after meeting certain stringent requirements. Track two verification is less strict. A track two project will be subject to the verification procedures established by the UNFCCC's Joint Implementation Supervisory Committee, which involves an independent entity determining whether the project meets the JI mechanism requirements and which are outlined under arts. 5 and 7 of the Kyoto Protocol (i.e. to establish and maintain a national system for the estimation and reporting of relevant GHG emissions by sources and removals by sink).

See “Joint Implementation (JI),” online: UNFCCC < http://ji.unfccc.int/index.html>.

FAITC, supra note 41.

Tim Williams \& Michelle Zakrison, The Climate Change Convention and the Kyoto Protocol (Ottawa: Parliamentary Information and Research Service, 2007) at 5. 
had a depreciating effect on the entire market for such credits, thus leaving those transition countries with little economic incentive to create actual "greened" credits.

Parties to the Kyoto Protocol can choose to implement internally regulated domestic or regional trading systems with the objective of regulating and reducing GHG emissions. The Kyoto Protocol does not specifically address requirements applicable to such trading systems, but does provide guidelines under which such systems may operate. The trading systems implemented by the parties will not necessarily be set up exclusively for trading Kyoto Protocol units, but will likely also take into account carbon credits generated domestically.

Canada's emission reduction target under the Kyoto Protocol is 6 percent below 1990 levels by the year 2012. ${ }^{52}$ On 10 March 2008, the Government of Canada announced the Regulatory Framework, ${ }^{53}$ which will be applicable to the reduction of GHG emissions. Based on the terms of this document, it is questionable whether Canada will be able to achieve the Kyoto Protocol's target.

A general sentiment has been expressed that the Kyoto Protocol has failed to accomplish its ultimate goal, that being the establishment of agreement amongst the world's largest GHG emitters on how to cut GHG emissions. Arguably, one of the major obstacles of the process surrounding the Kyoto Protocol was the failure of the U.S., one of the world's largest GHG emitters, to ratify the Kyoto Protocol. Nonetheless, one cannot discount the accomplishments achieved by designing the foundation of carbon credit trading in addition to the creation of Europe's Emission Trading Scheme (EU-ETS).

\section{CHINA AND INDIA - SHOULD THEY BE ANNEX I PARTIES?}

China and India are currently considered to be Non-Annex I parties. However, it has been widely recognized that their growing economies could fall under the definition of EIT, and as such, each would qualify as an Annex I party with resultant GHG emission reduction requirements. Although, as mentioned above, the per capita footprint of both China and India is much smaller than that of the U.S. and other large emitters, in 2006, China's $\mathrm{CO}_{2} \mathrm{e}$ aggregate emissions surpassed the U.S. by 8 percent. ${ }^{54}$ The 2007 IPCC Assessment Report forecasted that China's $\mathrm{CO}_{2} \mathrm{e}$ emissions would rise between 2.5 percent to 5 percent each year between 2004 and 2010. However, it appears that the estimates may be two to four times too low.

According to the U.S. Energy Information Administration (EIA), in 1990, China and India were responsible for 13 percent of the world's $\mathrm{CO}_{2}$ e emissions, with such share increasing Act - 2007 (Gatineau: Environment Canada, 2007) at 3.

Supra note 21.

Netherlands Environmental Assessment Agency (NEAA), Press Release, "China now no. 1 in CO2 emissions; USA in second position” (19 June 2007), online: NEAA <http://www.pbl.nl/en/news/press releases/2007/20070619Chinanowno1inCO2emissionsUSAinsecondposition.html>. 
to 22 percent in 2004 due to an increase in coal usage in those countries. ${ }^{55}$ It is expected that by 2030, the combined $\mathrm{CO}_{2} \mathrm{e}$ emissions of China and India will account for 31 percent of total world emissions, with China being responsible for 26 percent of the world's total as a result of increasing coal combustion. ${ }^{56}$ Furthermore, by 2030, China's coal-related emissions are expected to account for 48 percent of the world's total coal-related emissions and India for 8 percent. ${ }^{57}$ As the economies of these two countries expand, it is expected that the use of coal will increase substantially. According to the EIA, China and India account for 72 percent of the projected world increment in coal-related $\mathrm{CO}_{2} \mathrm{e}$ emissions. ${ }^{58}$ Total coal-related emissions from the non-OECD countries have been greater than those from the OECD countries since 1987, and in 2030, they are projected to be more than double the OECD total. ${ }^{59}$ China and India are not part of the OECD.

As mentioned earlier, the Kyoto Protocol established that the burden to reduce GHG emissions and the obligation to assist Non-Annex I parties rests on the shoulders of OECD and EIT countries, with China and India not having emission reduction commitments despite the fact that these two countries are larger contributors to GHG emissions into the atmosphere than numerous OECD countries.

\section{Alberta’s Greenhouse Gas Emissions Regulatory FrameWork}

Alberta has been a leader in the regulation of GHG emissions. In July 2007, Alberta became the first jurisdiction in North America to regulate the emission of GHGs when it introduced its Specified Gas Emitters Regulation ${ }^{60}$ pursuant to the Climate Change and Emissions Management Act. ${ }^{61}$ The Government of Alberta has always intended to develop a "made-in-Alberta" regulatory system. ${ }^{62}$ By taking a leading role, Alberta hoped to influence policy at the federal level to ensure a "prudent" approach and to assert its jurisdiction over its environment and natural resources. It remains to be seen exactly how successful Alberta will be in achieving this objective, but the federal Regulatory Framework on air emissions announced in March 2008 appears to set out a more stringent approach to regulating GHG emissions. $^{63}$

Energy Information Administration (EIA), International Energy Outlook: 2007 (Washington: U.S. Department of Energy, 2007), online: EIA <http://tonto.eia.doe.gov/ftproot/forecasting/0484(2007). pdf $>$ at $72-73$.

Ibid. at 74 .

Ibid. at 76 .

Ibid.

Ibid.

Alta. Reg. 139/2007 [SGER].

S.A. 2003, c. C-16.7 [CCEMA].

Bob Savage, “Taking Action, Alberta's Climate Change Strategy” (Presented to the Canadian Heavy Oil Association (CHOA), Calgary, 25 May 2006), online: CHOA <http://www.choa.ab.ca/ events_archive.html> at 26.

63

Regulatory Framework, supra note 21. 
Alberta is responsible for contributing 39 percent of Canada's total reported GHG emissions, ${ }^{64}$ and as such, emits more GHGs than any other province in Canada, with Ontario following at 28 percent, and Quebec and Saskatchewan each emitting 8 percent. $^{65}$

\section{Provincial Contributions to Total Reported Canadian Greenhouse Gas Emissions ${ }^{66}$}

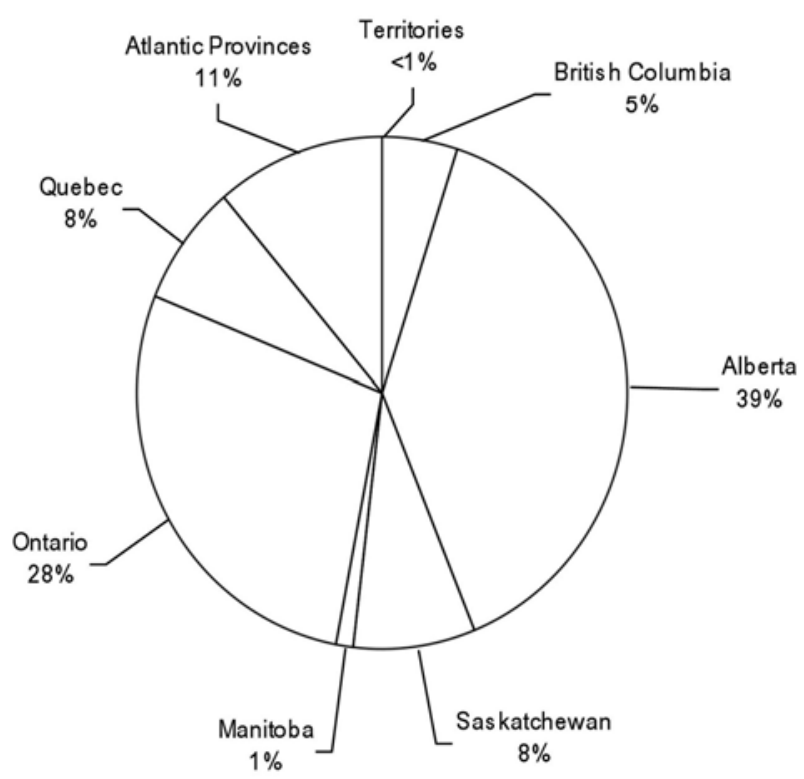

One of the primary reasons for Alberta's large volume of GHG emissions is its dependence upon coal-fired generation as its primary source of electricity. Unlike Ontario and Quebec, Alberta does not have commercial nuclear power and has limited hydroelectric power capacity. Alberta is also home to the oil sands, the second largest source of oil in the world. ${ }^{67}$ Extracting and processing of the oil sands, in addition to requiring huge amounts of natural gas and electricity, results in large volumes of $\mathrm{CO}_{2} \mathrm{e}$ emissions. With approximately 176 billion barrels of oil in the oil sands proven to be recoverable with today's technology and under current economic conditions, and an estimated additional 315 billion barrels potentially recoverable, exploitation of the oil sands is expected to continue to grow for the foreseeable future. ${ }^{68}$ Oil sands production is expected to at least triple by 2020. Output of

\footnotetext{
$64 \quad$ Specified Gas Reporting: Alberta’s 2004 Industrial Greenhouse Gas Emissions (Edmonton: Alberta Environment, 2006) at 22 [Specified Gas Reporting].

Ibid.

Ibid.

Alberta Energy, "Facts on Oil Sands” (June 2006), online: Alberta Energy <http://www.energy. gov.ab.ca/OilSands/pdfs/FactSheet_OilSands.pdf> ["Facts”]; Alberta's Oil Sands, online: Alberta $<$ http://oilsands.alberta.ca>. 
marketable oil sands production increased to 1.126 million barrels per day (bbls/d) in 2006. ${ }^{69}$ The Government of Alberta expects production could reach 3 million bbls/d by 2020 and possibly even 5 million bbls/d by $2030 .^{70}$ Crude bitumen upgrading in Alberta is projected to be about 1.4 million bbls/d day by 2011, compared with the 2006 level of 885,000 bbls/d. ${ }^{71}$ Currently, approximately 22 percent of the synthetic crude oil is produced in the Edmonton area. By 2011, the portion of bitumen upgraded in the Edmonton area could reach 25 percent of the total and 33 percent by $2020 .^{72}$

\section{Distribution of Total Industrial Greenhouse Gas Emissions by Facility Type ${ }^{73}$}

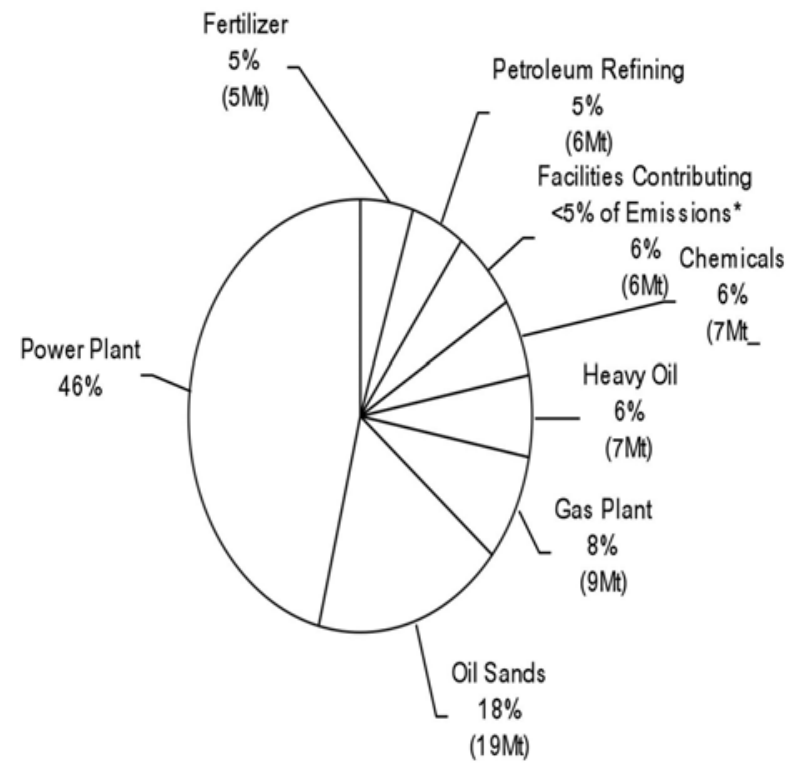

Although only a portion of the oil produced and refined in Alberta is consumed within the province, all of the GHG emissions generated by it are allocated to Alberta's inventory. Because energy is such an important sector of the Alberta and Canadian economy, the two levels of government have been extremely careful to draft legislation that will have the least possible economic impact, while still attempting to achieve the goal of reducing GHG emissions. Environmental groups have criticized both levels of governments for not taking a tough enough approach. sands.asp>.

Ibid.

Ibid.

Ibid.

Specified Gas Reporting, supra note 64 at 6. 
Industry contributes 51 percent of GHG emissions in Canada, followed by transportation and commercial and residential heating as the next largest sources. ${ }^{74}$

\section{Sources of Emissions of Greenhouse Gases ${ }^{75}$}

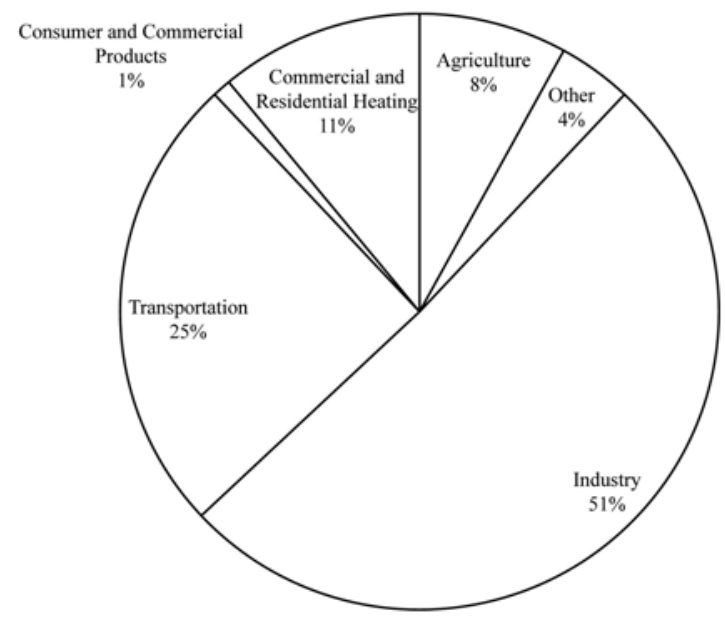

For this reason, regulation of industrial emissions is seen as one of the easiest and most direct ways to accomplish large-scale reductions of GHG emissions in Canada. Alberta has taken the lead with its SGER, which regulates industrial emitters in Alberta that emit more than 100 kilo-tonnes of GHGs annually. In Alberta, 99 large industrial facilities reported a total of 110 mega-tonnes of GHG emissions in 2004. This represented 47 percent of all GHG emissions in Alberta and 64 percent of all industrial emissions. ${ }^{76}$ It is evident that the Government of Alberta expects much of the growth in emissions between now and 2050 to come from industrial sources that can be reduced by the implementation of carbon capture and storage (CCS) systems. Alberta's plan is to reduce its emissions by 2050 by 200 megatonnes (that is, by 50 percent) from what they would be in a BAU scenario. ${ }^{77}$ This translates to an absolute reduction from 2005 levels of 14 percent, or approximately 29 mega-tonnes. This falls short of the federal government's target of 20 percent below 2006 levels by 2020, and much lower than the Kyoto Protocol target of 6 percent below 1990 levels by 2012. This is also less than the target set out by the Alberta government in its own CCEMA, which targeted reductions in emission intensity (relative to GDP) at 50 percent of 1990 levels by $2020 .^{78}$

Canada, Action on Climate Change and Air Pollution (Ottawa: Minister of Environment, 2007), online: ecoACTION <http://www.ecoaction.gc.ca/news-nouvelles/pdf/20060426-2-eng.pdf> at 5.

Ibid.

Specified Gas Reporting, supra note 64 at iii.

Alberta's 2008 Climate Change Strategy: Responsibility/Leadership/Action (January 2008), online: Alberta Environment <http://environment.gov.ab.ca/info/library/7894.pdf>.

Supra note 61, s. 3. 


\section{A. Climate Change and Emissions Management ACt}

The Government of Alberta assented to the CCEMA on 4 December 2003 and certain sections were proclaimed in force 1 November 2004. ${ }^{79}$ The CCEMA was amended in April 2007 by the Climate Change and Emissions Management Amendment Act ${ }^{80}$ to add a number of enforcement sections and to revise some other sections. Section 3 of the CCEMA states that "the specified gas emission target for Alberta is a reduction by December 31, 2020 of specified gas emissions relative to [GDP] to an amount that is equal to or less than $50 \%$ of 1990 levels" and also provides that the government may make regulations: (1) "establishing interim specified gas emission targets"; and (2) "establishing specified gas emission targets and interim specified gas emission targets for different specified gases and for different sectors of the Alberta economy." ${ }^{81}$ This provision allows the government to treat different sectors differently if it deems it prudent to do so. To date, the Alberta government has chosen to focus on regulating large emitters that emit 100,000 tonnes or more of GHGs into the atmosphere. It has done this through the SGER that came into force 1 July $2007 .^{82}$

Section 6 of the CCEMA imposes a duty on any emitter of specified gases to report any emissions of specified gases that are at or in excess of levels specified in the regulations. ${ }^{83}$ The CCEMA also permits the government to make regulations respecting emission offsets, credits and sink rights for the purpose of achieving reductions in specified gas emissions consistent with specified gas emission targets established under s. 3 and any sectoral agreements entered into under s. $4{ }^{84}$ To date, the Government of Alberta has not entered into any sectoral agreements pursuant to s. 4 and has opted instead to set out the general framework for their emissions management plan in the CCEMA and set out the specific targets, compliance mechanisms, and reporting requirements in the regulations to the CCEMA, specifically, the SGER and the Specified Gas Reporting. ${ }^{85}$ The CCEMA states that the regulations may include the description and nature of emission offsets, credits, and sink rights, and the manner in which emission offsets, credits, and sink rights may be created, obtained, distributed, traded, sold, used, varied, or cancelled. The CCEMA also provides for the establishment of one or more public registries for offsets and credits. ${ }^{86}$ Registration of projects and serialization of offsets or tonnes by the Alberta Emissions Offset Registry is seen as an integral component of establishing a viable offset trading market. In particular, it is essential to the integrity of any emissions trading system that offsets and credits be verified and registered to confirm their existence and then be retired once they are used. To ensure that offsets or credits can never be used more than once, it is essential that their cancellation or retirement be registered in the registry system. The Government of Canada has "allocated

\footnotetext{
Ibid.

Bill 3, Climate Change and Emissions Management Amendment Act, 2007, 3rd Sess., 26th Leg., Alberta, 2007 [CCEMAA].

Supra note 61, s. 3.

Supra note 60, s. 2.

Supra note 61 , s. 6.

Ibid., ss. 3-4.

Supra note 64.

Supra note 61, s. 5. The Alberta Emissions Offset Registry (AEOR) is now in place and can be accessed online: Carbon Offset Solutions <http://www.carbonoffsetsolutions.ca/aeor >. Now that the AEOR is in place, the government requires that offset projects must be registered in order to use offsets generated from an offset project to meet compliance requirements.
} 
[CDN]\$66 million over two years to set up key features of the regulations around its Turning the Corner plan, including an electronic tracking system [or registry] for units traded in the carbon market."87

The CCEMA also provides for the Government of Alberta to make regulations respecting compliance options, maximum prices for credits and penalties, and establishes the Climate Change and Emissions Management Fund (the Technology Fund). The SGER addresses these items specifically, including the price of Technology Fund credits. The amendments to the CCEMA that were enacted under the $C C E M A A^{88}$ were directed largely to adding a host of enforcement mechanisms, including the right of an investigator to enter and inspect at a facility without a warrant, and the right to copy or take evidence or documentation. ${ }^{89}$ The CCEMA sets out offences under the $A c t^{90}$ and prescribes penalties for committing an offence, ${ }^{91}$ administrative penalties, ${ }^{92}$ and liability for directors and officers. ${ }^{93}$

\section{B. SPECIFIED GAS EMITTERS REGULATION}

\section{EMISSION REDUCTION TARGETS}

The SGER came into force on 1 July 2007 as the main regulation to accompany the CCEMA. ${ }^{94}$ The SGER requires emitters that emit 100,000 tonnes of GHGs or more annually to reduce their emission intensity by:

- 12 percent for established facilities (facilities that completed their first year of operations before 1 January 2000), and

- for new facilities (facilities completing their first year of operations after 1 January 2000), no reduction is required in the first three years of operation and then 2 percent is required for each additional year a facility has operated, up to a 10 percent reduction requirement for facilities in the eighth year of operation at the end of 2007,

below the baseline emission intensity (BEI) established for the facility. ${ }^{95}$ The BEI for an established facility is based on the ratio of the total annual emissions of production for 2003-

Environment Canada, News Release, "Baird and Fortier Welcome Carbon Market Announcement by Montreal Climate Exchange” (14 March 2008), online: Environment Canada <http://www.ec.gc.ca/ default.asp?lang=En\&n=714D9AAE-1\&news=A3FF6D8B-5DE5-4891-8F3F-915C2FD33151>. Supra note 80.

Supra note 61, s. 13.

Ibid., s. 44.

Ibid., s. 45.

Ibid., s. 38.

Ibid., s. 48.

Supra note 60.

Ibid., ss. 3-4. 
2005. ${ }^{96}$ The BEI for a new facility simply uses the third year of emissions divided by the production in the third year.

Alberta has adopted an emission intensity approach as opposed to an absolute reduction approach. The emission intensity (EI) approach is designed to be linked to GDP where EI $=(\mathrm{E} / \mathrm{P})$ where $\mathrm{E}=$ emissions and $\mathrm{P}=$ number of units produced. This approach was preferred over an absolute reduction approach to allow the economy to continue to grow while still reducing EI. Otherwise, it was felt that without rapid technological breakthroughs, the only way to achieve meaningful reductions would be to reduce production, but this was not considered acceptable.

Under the $S G E R$, if a regulated emitter fails to comply with the emission reduction limits prescribed, the emitter will be subject to a fine of CDN\$200 per tonne of GHGs that is released over the net emission intensity (NEI) limit. ${ }^{97}$ At the time of writing, emitters are in the process of completing their submissions to Alberta Environment and it is unknown whether any emitters will be subject to such a fine for failure to comply. However, given the size and sophistication of the regulated emitters, it is highly unlikely they would risk such a heavy fine when compliance mechanisms such as offsets and Technology Fund credits are so much less expensive. Alberta Environment has also indicated that it will work with emitters to assist them in meeting their compliance obligations while all parties become acquainted with the system rather than being quick to impose penalties.

\section{COMPLIANCE MECHANISMS}

The SGER sets out a number of compliance options that are intended to provide the regulated emitter with some flexibility in meeting its reduction targets. The emitter can choose to do one or any combination of the following:

- $\quad$ reduce its actual emission intensity;

- $\quad$ purchase Technology Fund credits at \$15 per tonne of GHG emissions reduction required; or

- $\quad$ purchase Emission Offset credits.

\section{TEChNOLOGY FUND}

The Technology Fund, is intended to allow emitters to pay into the fund to purchase Technology Fund credits to meet their emission reduction targets. The money amassed in the Technology Fund from the purchase of these credits is to be used to invest in and deploy new and existing technologies and equipment to reduce GHG emissions, including energy efficiency technologies, alternative and renewable energy sources, and conservation projects.

96 Baseline emission intensity for an established facility is calculated by dividing the total annual emissions for 2003, 2004, and 2005 by the production in each of those years and taking the average for the three years. Ibid., s. 21(1)(a). 
Interestingly, it is also earmarked to "improve Alberta’s ability to adapt to climate change."98 It is uncertain what that means or entails, but it is certainly broad enough to include economic measures that would assist in softening the blow to industry or Alberta's citizens.

There are some restrictions on the use of Technology Fund credits. Unlike an offset, under the regulations, a Technology Fund credit purchased before 31 March in any year can only be used for meeting emission reduction targets for the previous year. A fund credit purchased after 31 March can only be used to meet targets for that year. ${ }^{99}$ In essence, if the fund credits are not used in the year for which they were purchased, they expire.

There are a couple of key reasons that emitters have found fund credits to be a preferable way of meeting their targets. First, unlike offsets, there is basically no risk to an emitter to use fund credits to meet compliance. The government issues them so their validity cannot really be challenged. Second, the funds contributed to the Technology Fund by the purchase of Technology Fund credits are subsequently made available to emitters and others to invest in emission reduction technologies, such as CCS projects. A number of the large emitters in Alberta fully expect to have at least a portion of their Technology Fund contributions returned to them in the form of grants from the provincial government to assist them in funding their CCS projects. Further, several emitters have indicated that they believe that investment in long-term technologies such as CCS is the most effective way for Alberta industry to permanently address long-term GHG reductions. Emitters would prefer to actually "go green" and reduce emissions in the long-term rather than continuing to emit large volumes of GHGs and have the public criticize them for simply "buying their way out" of the problem by purchasing offsets. Most environmental groups would prefer to see large emitters take steps to reduce their emissions at the source rather than comply by purchasing offsets. This position does not seem to appreciate the economic efficiencies of an offset trading system.

\section{EMISSION PERFORMANCE CREDITS}

Emission Performance Credits (EPCs) are defined in the SGER as a reduction in the release of specified gases, expressed in tonnes of $\mathrm{CO}_{2} \mathrm{e},{ }^{100}$ that meet the requirements of s. 9. ${ }^{101}$ Under s. 9, regulated emitters generate EPCs when their facility's actual emission intensity for a period is less than the applicable NEI limit for that period. ${ }^{102}$ The amount of emission reductions not used in that period constitutes an EPC. EPCs can be used for compliance in subsequent periods or they can be traded for use at other facilities. However, EPCs must be held by persons responsible for using them. If the facility expects to achieve similar reductions in the future and do not think that they will require their EPCs for their

Climate Change and Emissions Management Act, S.A. 2003, c. C-16.7, s. 10(3).

SGER, supra note 60, s. 8(3).

Each GHG has a GWP factor, which indicates how many tonnes of $\mathrm{CO}_{2}$ would be required to produce the same GWP. For example, methane $\left(\mathrm{CH}_{4}\right)$ has a GWP of 21, making it 21 times more potent as a GHG than $\mathrm{CO}_{2}$. Alberta Environment, Offset Credit Project Guidance Document (February 2008), online: Alberta Environment <http://environment.alberta.ca/documents/Guidance_Document_Alberta_ Offsets_v.1.2_Feb_08.pdf > at 5-6 [Offset Credit Guidance Document].

Supra note 60, s. 9.

Ibid. 
own compliance, they may opt to sell all or a portion of the EPCs to another regulated facility and monetize their reduction achievements. Similarly, if they feel that they can sell their EPCs to another facility for more than it will cost to purchase offsets to replace them, they may sell them and take the profit. ${ }^{103}$ Finally, like all other types of offsets and credits, EPCs can only be used once.

\section{EMISSION OFFSETS}

Emission Offsets are defined in the SGER as a reduction in the release of specified gases, expressed in tonnes of $\mathrm{CO}_{2} \mathrm{e}$, that meet the requirements of s. $7 .{ }^{104}$ Emission Offsets are generated by non-regulated activities taken by a person on or after 1 January 2002 that reduce emissions. Section 7 provides that to qualify as an Emission Offset, the emission reduction must:

- $\quad$ occur in Alberta;

- be from an action taken that is not required by law at the time activity is started;

- be from actions taken on or after 1 January 2002 or occur on or after 1 January 2002;

- $\quad$ be real and demonstrable; and

- be quantifiable and measurable, directly or by accurate estimating using replicable techniques. ${ }^{105}$

Like EPCs and Technology Fund credits, Emission Offsets can only be used once. However, there are other distinct advantages to using Emission Offsets to meet reduction targets. Like EPCs, but unlike Technology Fund credits, Emission Offsets can be used in any year. There is no provision for expiry under the SGER. Unlike EPCs, Emission Offsets do not need to be generated from your own activities, but can be generated from a variety of activities such as the generation of renewable clean energy, energy efficiency projects, and projects that reduce emissions by non-regulated facilities.

To date, one of the key advantages of Emission Offsets in Alberta is that they are less expensive than Technology Fund credits. The main reason for this is that they are typically discounted for risk. Whereas Technology Fund credits have little or no risk attached to them, there is some degree of risk associated with an Emission Offset. The risk stems from the fact that these Emission Offsets are not issued by the government and in certain instances, may not be accepted by Alberta Environment. It is possible (although unlikely in most cases) that an emitter may submit Emission Offsets as part of its compliance requirement only to find out subsequently that for one reason or another, the Emission Offsets are not acceptable. The 
risk of this occurring is mitigated by the project verification process that is required under the SGER. ${ }^{106}$ The verification process is conducted by a qualified independent verifier to ensure that the GHG Assertion ${ }^{107}$ of the project developer is accurate and follows the applicable Alberta Environment protocols. In addition, emitters will typically conduct extensive due diligence on the project prior to purchasing the Emission Offsets from the project developer.

Another major advantage of Emission Offsets is that they do not expire and can be used for any year. This allows emitters to purchase Emission Offsets and bank them and either use them for future compliance periods or sell them, potentially at a profit. ${ }^{108}$

One of the features of the Alberta Emission Offset system that limits the development of a vibrant offset market is that unlike the proposed federal framework, there is no limit on the number of Technology Fund credits that emitters can purchase to meet their compliance requirements. The result of this is that in Alberta, the demand for Emission Offsets will depend upon the significance of the discount that they are trading at versus the Technology Fund credits, and the assessment of the risks associated with the project. Sellers of Emission Offsets can reduce this risk by contracting to replace any Emission Offsets that are not accepted with acceptable Emission Offsets, but the value of such a contractual commitment will hinge upon the creditworthiness of the seller. This has been an issue so far as the market is in its nascent stages and is populated by aggregators and project developers who for the most part, although entrepreneurial, have not had the time or resources to establish creditworthiness. Trades of Emission Offsets in Alberta have reportedly ranged from a low of CDN\$4 per tonne, up to \$13 per tonne. The major volume of Emission Offsets traded has come from agricultural zero-till or low-till projects, since these projects were amongst the easiest to quantify, aggregate, and verify in the short time period available. In addition, the Tillage Quantification Protocol was one of the first protocols approved by Alberta Environment. ${ }^{109}$

\section{OFFSET SYSTEM DESIGN}

Alberta's offset system is intended to bring forward project-based GHG reductions and removals from actions that are beyond BAU, including those that are not driven by Alberta regulations. Regulated firms can purchase verified emission reductions and/or removals of GHGs (for example, Emission Offsets) from voluntary actions arising from unregulated activities (for example, offset projects) in Alberta (the Offset System). Emission reductions could come from projects that reduce emissions at a source (for example, so-called direct emission reductions or indirect emission reductions that entail clean energy projects that displace fossil fuel based energy), or through sequestration (actions that remove GHG

106 For a detailed discussion of the verification process, see Alberta Environment, Offset Credit Verification Guidance Document (September 2007), online: Alberta Environment <http://environment. alberta.ca/documents/Verification_Document_Alberta_Offsets_v1_Sept_07.pdf $>$.

Ibid. at 3: the GHG Assertion is the claim of emission reductions arising from an offset project being asserted by the project developer.

See the discussion of the development of the offset market in Canada in Part III, below.

Alberta Environment, Quantification Protocol for Tillage System Management (February 2008), online: Alberta Environment <http://environment.alberta.ca/documents/Tillage_Protocol_vl.3_Feb_08.pdf >. 
emissions from the atmosphere, such as improved management of agriculture soil carbon or geological sequestration of $\mathrm{CO}_{2} \mathrm{e}$ through CCS).

Alberta Environment and its consultative agencies have designed Alberta's Offset System based on the following key principles:

- $\quad$ administrative simplicity: the Offset System, including design, implementation, and key functions, is to be administered in a simple, cost-effective, and timely manner;

- maximum scope: the Offset System should, over time and to the extent practical, promote and enable projects in all sectors and of all types and size;

- $\quad$ building and linking: the Offset System should seek to maximize efficiency and resources by building on and linking with existing programs and trading systems;

- $\quad$ transformational change: the design should support transformational change across all sectors of the economy and society in such a way that emission reductions and removals are a part of daily decision-making by Albertans. This change will be enabled, in part, by the deployment of proven, enhanced, and innovative technologies with support from public education, regulatory, and other policy direction to drive the behaviours necessary to contribute to overall reductions;

- $\quad$ environmental benefits: the design must ensure that project-based offsets result in further reductions and removals in GHG emissions than would be the case if Emission Offset credits were not available. Other environmental benefits can be addressed when considering project eligibility; and

- $\quad$ transparency and accountability: to earn public confidence and mitigate conflicts of interest, the Offset System must maximize opportunities for public scrutiny and input at the level of individual projects and ensure robust and independent verification of emission reductions and/or removal enhancements while respecting confidential business information. ${ }^{110}$

The Alberta Offset System (see Figure 1, below) is designed to function in a timely and cost-effective manner while ensuring that: (1) quality projects are developed in a manner that goes beyond BAU; and (2) credible reductions and/or removals are verified. The Offset System recognizes the need to balance environmental integrity with the ability to commercialize market opportunities.

The Alberta Offset System relies on ex post verification. This means that the Emission Offsets are first created and then verified (Figure 1). In other systems, like that proposed by the Government of Canada, a mandated validation step sometimes occurs before projects can begin and where a governmental authority reviews a project application document. In these systems, the governmental authority assesses whether the project fits the eligibility of the 
system at hand and is legitimately going to result in the proposed amount of Emission Offsets stated in the application.

Figure 1:

\section{The Alberta Offset System at a Glance}

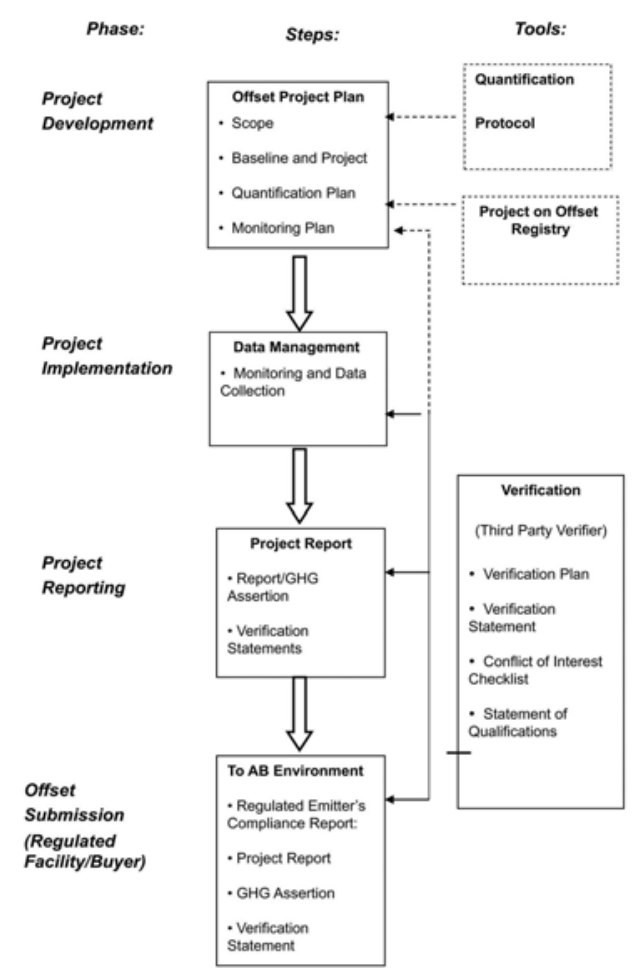

The Alberta government believes that minimizing the administrative cost and time burden of the offset cycle is key to allowing businesses to find efficient and effective solutions to reducing GHGs through the Alberta offset market. The role of government in this market is to set out the above elements of the system and to enable the private sector (buyers and sellers) to develop and trade this new environmental commodity.

The following core elements comprise the Alberta carbon offset market:

- market demand that is created through the regulations and by setting emission reduction targets for regulated emitters;

- $\quad$ market supply of offsets and performance credits allowed by the regulation;

- $\quad$ market rules established by the Alberta government in the regulation;

- market tools for the quantification of protocols and a registry that helps facilitate supply; and 
- $\quad$ regulatory backstop which includes consequences for non-compliance to firmly establish the demand.

\section{MARKet Supply AND Rules - CARBOn OfFSETS IN Alberta}

In general, an Emission Offset is generated when a project results in GHG reductions or removals that go beyond normal business operations, or common industry practice (that is, BAU or baseline), and results in lower emissions (if Emission Offset credits were not available). ${ }^{111}$ This usually involves changing a business practice or installing a technology or control system to reduce emissions, or storing carbon in biological sinks.

In Alberta's project-based system, the GHG emissions baseline is calculated before the practice or technology is implemented and then emissions calculated after the practice is changed. The difference between baseline minus the project emissions equals the offset credit amount, and is measured in tonnes of emission reductions.

In addition to the requirements specified in the SGER, Alberta Environment has also expressed that Emission Offsets must be verified by a qualified third party and have clearly established ownership. ${ }^{112}$ To meet these criteria, a number of market tools known as GHG Quantification Protocols have been developed by the Alberta government to seed the market. A process for industry to cost-share in the development of new protocols has also been established to ensure that new and innovative technologies can enter the system. These types of tools are a feature of every project-based carbon market in existence or being contemplated and are discussed in more detail in the next section.

\section{PRotocols}

GHG Quantification Protocols, approved by the Alberta government, help the market to function by creating certainty and confidence in the commodity being generated. The protocols also provide for quality assurance, thereby reducing the risk and cost for buyers and sellers. In Alberta, project developers must use a government-approved protocol to sell compliance-based offsets in the province.

Alberta has some of the most stringent legal requirements in the world for defining compliance-based carbon offsets. Alberta's SGER stipulates that Emission Offset credits are to be real, measurable, and verifiable. ${ }^{113}$ These offset eligibility criteria require that all GHGs affected by a project are taken into account in order to be a real reduction, and that demonstrable and verifiable reductions have occurred. ${ }^{114}$ Alberta has chosen to base offset protocols on the International Organization for Standardization (ISO) 14064-2 Standard ${ }^{115}$

111 This is a foundational element of any offset system; however, application will be evolutionary.

112 For more information see online: Carbon Offset Solutions <http://www.carbonoffsetsolutions.ca>.

113 Supra note 60, s. 7.

114 The European Union Emissions Trading Scheme has recently started to consider including nitrous oxide in its emissions trading system and these are for government-issued allowances, and not offset credits. Many of the standard methods defining offsets under the Chicago Climate Exchange account for $\mathrm{CO}_{2}$ only.

See International Organization for Standardization (ISO), online: ISO <http://www.iso.org>. 
as a framework for quantification and development. This framework ensures that a streamlined life cycle assessment is conducted for all sources and sinks upstream, on-site, and downstream of the project, and the baseline condition, providing a thorough and comprehensive analysis of relevant GHG factors.

Both of these elements, stringent definitions of a carbon offset and adherence to the ISO 14064-2 framework, make quantification protocol development for the Alberta Offset System a rigorous, and in some cases, onerous task. However, they also provide for a high degree of environmental integrity and quality in the fundamentals of the resultant carbon offsets and increase compatibility with other trading systems.

The protocols basically define science-based accounting requirements for the practices and technologies that can be used to create Emission Offsets, the record-keeping and data collecting procedures, and the calculation methods for determining the emission reductions and resultant Emission Offsets. The Alberta protocols utilize formulas and GHG emission factors drawn from best practice guidance from around the world to form the backbone of the protocols so that direct GHG measurements are not always needed. The use of estimates are critical since direct GHG measurements can be cost prohibitive.

These protocols have been developed using the best available science in Alberta, good practice guidance, provincial and national expertise, and experience gained through similar international projects. The approved protocols are available to project developers to use immediately and also serve as guidance for those who want to develop quantification approaches unique to their circumstances in the future.

The availability of a quantification protocol is expected to decrease development costs and reduce risk for buyers and sellers when implementing projects. The protocols provide a strong framework upon which to base the offset project plan, with accompanying quantification, monitoring, and quality assurance and/or quality control sub-plans. In addition, the verification process will be more efficient if the verifier company can reference a GHG Quantification Protocol applied to a specific project.

Over the short term, the Alberta government believes the focus of the offset market should be on learning the system and ensuring maximum transparency as project developers begin to create credits and trade this new commodity. For this reason, the availability of government-approved quantification protocols will provide the credibility needed in the early days of the market. ${ }^{116}$ 


\section{CANAdA's Proposed REgulatory Framework fOR AIr EMisSions}

\section{A. Bill C-30: Canada's Clean Air ACt}

Bill C-30, an Act to amend the Canadian Environmental Protection Act, 1999, [CEPA 1999], the Energy Efficiency Act and the Motor Vehicle Fuel Consumption Standards Act (Canada's Clean Air Act), was introduced in the House of Commons and given first reading on 19 October 2006.

Two days after it was tabled, the government published a Notice of intent to develop and implement regulations and other measures to reduce air emissions. The Notice set out the government's intention to develop and implement a number of regulations under CEPA 1999 and to address air pollutants and greenhouse gases using the amendments put forward in Bill C-30. ${ }^{117}$

The Bill was subsequently rejected by Parliament and was referred to the Legislative Committee before the second-reading stage. The Legislative Committee has revised the Bill and the short title is now Canada's Clean Air and Climate Change Act. The Bill retains its original intent of implementing regulations and other measures to reduce air emissions, but it has a renewed focus on meeting Canada's obligations under the Kyoto Protocol. The fate of Bill C-30 is unknown at this time, but it will likely be difficult for any government to reverse the progress that is being made to develop a regulatory framework for the reduction of air emissions. Arguably, any revisions to the regulatory framework will be to make it more stringent, not less.

\section{B. FEDERAL REgULATORY FRAMEWORK ON AIR EMISSIONS}

On 10 March 2008, the Government of Canada released the final version of its action plan, Regulatory Framework. ${ }^{118}$ According to the federal government, this version elaborates upon and strengthens the government's previous Regulatory Framework for Air Emissions, which was released in April 2007. ${ }^{119}$ Rather than discuss the differences between this version and the earlier one, the focus will be on the features of the framework as finally determined. The focus remains to reduce GHG emissions to 20 percent below 2006 levels by $2020 .{ }^{120}$ Draft regulations based on the Regulatory Framework are scheduled to be published in the fall of 2008 and to become binding on 1 January 2010.

Frédéric Beauregard-Tellier et al., Legislative Summary: Bill C-30: Canada's Clean Air and Climate Change Act (14 November 2006, revised 19 April 2007), online: Parliament of Canada <http://www.parl.gc.ca/39/1/parlbus/Chambus/house/bills/summaries/c30-e.pdf> at 1-2; Canadian Environmental Protection Act, 1999, S.C. 1999, c. 33; Energy Efficiency Act, S.C. 1992, c. 36; Motor Vehicle Fuel Consumption Standards Act, R.S.C. 1985, c. M-9.

Supra note 21. Most of the factual material contained in this summary of the federal Regulatory Framework on air emissions come directly from the government's Regulatory Framework. The authors have deemed it more efficient to reflect this in one footnote, rather than numerous footnotes. The interpretation and opinions on the summary are those of the authors. 2007), online: ecoACTION <http://www.ecoaction.gc.ca/news-nouvelles/pdf/20070426-1-eng.pdf> . Compare this to Alberta's commitment to reduce GHG emissions by 14 percent of 2005 levels by 2050 . 


\section{REDUCTION TARGETS FOR EXISTING FACILITIES}

Like Alberta, the Regulatory Framework has adopted an emission intensity reduction approach, rather than an absolute reduction approach. The Regulatory Framework will require existing facilities to achieve an emission intensity reduction target of 18 percent below 2006 levels by the beginning of 2010, followed by a continuous annual intensity improvement of 2 percent thereafter. ${ }^{121}$ This target will be applied to regulated sectors on either a facility-specific, sector-wide, or a company-by-company basis. ${ }^{122}$ The facilityspecific basis will be applied to sectors in which facilities are complex and diverse or where emissions are affected by factors beyond the control of facility operators. This will include oil sands production and upgrading, petroleum refining, natural gas pipelines, and upstream oil and gas. ${ }^{123}$

\section{REDUCTION TARGETS FOR NEW FACILITIES}

New facilities are defined in the Regulatory Framework as facilities whose first year of operation was 2004 or later. ${ }^{124}$ These facilities will be granted a three-year grace period during which no emissions intensity targets will apply. Targets will begin to apply in a new facility's fourth year of commercial operation based on emission intensity in its third year, with a 2 percent continuous annual emission intensity improvement required. ${ }^{125}$ Notably, the definition of new facility has been expanded to include not only completely new facilities, but also major expansions constituting more than a 25 percent increase in a facility's physical capacity as well as major transformations to a facility that involve significant changes to its processes. ${ }^{126}$ This may capture expansions planned by Suncor and by Canadian Natural, whose Horizon Project is scheduled to start up in the third quarter of this year, but which also has several expansion phases planned.

Further, emission intensity targets for new facilities will be based on a cleaner fuel standard to encourage continuous emission intensity reductions over time. The method of applying this cleaner fuel standard has yet to be disclosed. For upstream oil and gas and natural gas pipelines, a sector-specific approach will be applied. For the oil sands, the application will be process-specific, with a separate standard being applicable to each of mining, in situ recovery, and upgrading. ${ }^{127}$

\section{LOWER THRESHOLDS FOR REGULATION}

In certain regulated sectors, the Regulatory Framework will apply only to facilities exceeding a minimum annual emissions threshold. For natural gas pipelines, that threshold will be 50,000 tonnes of $\mathrm{CO}_{2}$ e per year. For upstream oil and gas facilities, it will be only 
3,000 tonnes of $\mathrm{CO}_{2}$ e per facility and 10,000 barrels of oil equivalent per day per company. ${ }^{128}$ These proposed thresholds are significantly stricter than the current Alberta regulatory threshold of 100,000 tonnes of $\mathrm{CO}_{2}$ e per year per facility ${ }^{129}$ and will capture a much larger number of companies that are not currently required to reduce emissions.

\section{Carbon Capture And StORAge}

The new Regulatory Framework recognizes the role of CCS in meeting overall emission reduction targets and references the recent report of the ecoENERGY Carbon Capture and Storage Task Force, which estimated that the Canada-wide potential for CCS could be as high as one-third to one-half of Canada's projected GHG emissions in $2050 .{ }^{130}$ The Regulatory Framework will provide an incentive for new facilities brought on stream in 2004 or later to adopt CCS, although it is not yet clear exactly what these incentives will be and how they will work. ${ }^{131}$ The federal government intends to set targets based on the implementation of CCS for in situ facilities and upgraders in the oil sands sector and for new coal-fired electrical generation plants that begin operating in 2012 or later. While the exact nature of these targets have not yet been determined, they are intended to become operative in 2018. Effectively, all oil sands and coal-fired generation facilities starting operations in 2012 or later will be expected to incorporate CCS. ${ }^{132}$

\section{COMPLIANCE MECHANISMS}

To provide emitters some flexibility in the measures they can take to meet their emission reduction targets, four separate compliance mechanisms are provided in respect of the above targets: Technology Fund contributions, offset credits, clean development credits, and credits for early action. At the outset, the most significant of these compliance mechanisms will be Technology Fund credits, since they will be the easiest to access and emitters can use them to meet up to 70 percent of their reduction obligations. ${ }^{133}$ In addition, the pre-certified credit option will be attractive to oil sands producers and coal-fired generating plants to subsidize the construction of their CCS systems. Producers can use any combination of the compliance mechanisms, provided they don't exceed the stipulated limits for Technology Fund credits and CDM credits.

\section{TECHNOLOGY Fund}

Similar to Alberta's regulations, regulated entities under the Regulatory Framework will be able to contribute to the Technology Fund in order to comply with emission intensity reductions. The contribution rate will increase over time, beginning at CDN\$15 per tonne of $\mathrm{CO}_{2}$ for the 2010-2012 period, rising to $\$ 20$ per tonne in 2013, and thereafter increasing at

Ibid. at 8.

SGER, supra note 60, s. 2.

The ecoENERGY Carbon Capture and Storage Task Force, Canada's Fossil Energy Future: The Way Forward on Carbon Capture and Storage (9 January 2008), online: Natural Resources Canada <http:// www.nrcan-rncan.gc.ca/com/resoress/publications/fosfos/fosfos-eng.pdf> at x, 2. Supra note 21 at 3.

Ibid. at 10-11.

Ibid. at $114-15$. 
the nominal rate of GDP growth. ${ }^{134}$ Contribution limits will decline correspondingly from 70 percent of a firm's total regulatory obligation in 2010 to 0 percent in 2018. This means that actual reductions by regulated facilities and/or companies and the purchase of offsets generated by non-regulated emission reductions will become increasingly important to a firm's ability to maintain compliance. ${ }^{135}$ Monies raised through contributions to the Technology Fund will be used to invest in technology to reduce GHG emissions, emphasizing reductions in the near term.

Of key importance to oil sands and coal-fired electricity generators is the "pre-certified investment option." ${ }^{36}$ This alternative allows companies and facilities to receive credits for investing directly in large-scale and transformative projects that are either its own or a joint venture project, provided they are selected from a menu set out by the federal government. ${ }^{137}$ "Pre-certified investments will have the same contribution rate as the [Technology Fund] and will be subject to equivalent criteria and requirements."138 It is not clear whether or not the emitter will receive one credit for each $\$ 15$ invested in such projects, ${ }^{139}$ or whether it will be some fraction of a credit.

The federal government intends to begin discussions with industry and the provinces of Alberta and Saskatchewan to pre-certify CCS projects. To encourage investment in CCS projects, oil sands producers and coal-fired generation plants will be able to satisfy 100 percent of their regulatory obligations by investing in pre-certified CCS projects up to 2018. Contributions to other funds such as provincial Technology Funds may also be recognized under the federal Regulatory Framework if they meet all the necessary equivalency requirements. ${ }^{140}$

\section{OFFSETS}

Similar to the Alberta system, the offset system contemplated in the Regulatory Framework is intended to encourage emission reductions from activities outside of the regulated sphere, allowing non-regulated entities to participate in and benefit from emission reduction activities. Offset credits will be generated for activities that result in real, incremental, quantified, verifiable, and unique emission reductions. In order to generate offset credits, project proponents must propose and receive approval for emission reduction activities that will be verified before offset credits will be issued to the project proponent. Those credits can then be sold to regulated entities for use in compliance or non-regulated purchasers that wish to either cancel the offset credits or bank them for future use or sale. It is expected that offsets may be in short supply due to the limited number of offset generating projects that will be available to draw from in the early years. This may cause upward price pressure and actually make offsets more expensive than Technology Fund credits. This is a key distinction from the Alberta system, where emitters would almost certainly purchase

Ibid. at 3.

See discussion of offsets in Part III.B.7, below.

Regulatory Framework, supra note 21 at 16.

Ibid.

Ibid.

Or whatever the price for a credit is in effect for the period during which the investment took place.

Supra note 21 at 16. 
Technology Fund credits at \$15 if offsets were more expensive. However, since the Regulatory Framework will force emitters who do not meet reduction targets to use offsets to satisfy at least 30 percent (and rising to 100 percent) of their remaining compliance requirements, some analysts are expecting offsets prices of \$20-\$25 at the outset. Some emitters, anticipating a shortage or increase in price, have begun buying offsets on a goforward basis to ensure they cover their offset requirements. The only factor that may dampen the demand and price for offsets is the availability of the pre-certified credit option, which allows emitters with qualifying projects to satisfy 100 percent of their compliance requirements by investing in pre-certified CCS projects up to $2018 .{ }^{141}$ However, if the investment is not credited on a dollar-per-dollar basis, emitters may find it more economical to simply purchase offsets.

\section{Clean DEVELOPMENT MECHANISM CREDITS}

Under the Regulatory Framework, regulated entities will also be able to purchase credits created through the CDM of the Kyoto Protocol. The purchase of such emissions reduction credits will be restricted to 10 percent of each firm's regulatory obligation, with the added restriction that credits generated through forest sink projects will not be available for use in complying with the Canadian regulations. ${ }^{142}$

\section{EARLY ACTION CREDITS}

Finally, a one-time credit of up to 15 mega-tonnes worth of emissions credits will be awarded to regulated entities for emission reduction activities undertaken between 1992 and 2006. These credits will be both tradable and bankable. The criteria for these credits are suspected to be similar to the criteria for past 2008 reductions. Emitters will share the 15 mega-tonnes of credits on a pro rata basis, based on their emission reduction volumes. ${ }^{143}$

\section{Federal Plan Vs. AlBerta Plan}

The Regulatory Framework appears to be materially different from the existing Alberta GHG emissions regulations in a number of respects. Regarding the Technology Fund and the comparable Climate Change and Emissions Management Fund in Alberta, only the federal Technology Fund incorporates both increasing contribution rates and decreasing contribution limits over time. The Alberta regulations do not contemplate linkages with the Kyoto Protocol or other emission trading schemes and do not provide for recognition of early action towards emission reductions. However, Alberta's regulations do allow credits generated from 2002 forward as opposed to 2008 forward under the federal plan. As well, Alberta's reduction requirements are only 12 percent for existing facilities versus 18 percent, plus an additional 2 percent per year, as discussed above under the federal Regulatory Framework. Unlike the Regulatory Framework, there is also no provision for continuous annual emission intensity improvements in the Alberta regulation. 
Finally, as noted above, the applicability threshold for certain sectors is significantly lower in the federal Regulatory Framework. Although the federal government has repeatedly indicated its intention to exempt provinces with equally stringent GHG regulations from the applicability of federal regulations, it remains to be seen whether Alberta's regulatory scheme will be deemed equivalent or whether Alberta will move towards harmonization with the proposed federal regulations. The differences will inevitably cause certain challenges for any harmonization efforts. To meet the equivalency requirement set out in the Regulatory Framework, Alberta will likely have to increase its requirements to match federal reduction targets, but may be able to get credit for three years of additional intensity reductions from 2007-2009. Depending on how federal-provincial harmonization discussions proceed, constitutional battles may result if consensus cannot be reached. It is uncertain how vigorously the Alberta government, or even industry within Alberta, will fight to avoid the more stringent requirements of the federal system.

\section{OFFSET SySTEM DESIGN}

The national offset system design is still in its infancy. The federal government released a series of documents that provided further detail on the design of the Regulatory Framework.

The key principles underlying the design of the national offset system are strikingly similar to the Alberta Offset System and include the following:

- $\quad$ environmental benefits: offset projects that achieve GHG reductions and a net environmental benefit;

- $\quad$ reductions occur in Canada: GHG reductions are domestic;

- maximum scope: the system promotes projects in as many sectors and for as many project types as is practical;

- $\quad$ administratively simple: the system is as simple and cost-effective to administer as possible, and the burden for participants is minimized; and

- $\quad$ build on experience: the system builds on the experience gained from the Canadian pilot projects and project-based crediting systems in other jurisdictions.

The project cycle for the national offset system is more complex and potentially more administratively burdensome than the Alberta Offset System:

- a protocol developer creates a quantification protocol for the project type and Environment Canada approves the protocol;

- $\quad$ the project developer applies to have its project registered;

- $\quad$ Environment Canada reviews, approves, and registers the project; 
- the project developer reports the GHG reductions achieved from a registered project and ensures that a verifier has provided a reasonable level of assurance on the reductions claim; and

- $\quad$ Environment Canada certifies the reductions and issues offset credits. ${ }^{144}$

The federal government has also signalled its intent to phase in the national offset system. The Government intends to start the system with a restricted set of projects, according to the following protocols (again, only government-approved protocols are allowed to be used to generate offset credits in Canada):

- $\quad$ landfill gas capture and destruction;

- $\quad$ anaerobic biodigesters;

- $\quad$ afforestation and/or reforestation;

- $\quad$ soil management (reduced tillage); and

- $\quad$ renewable electricity (non-emitting). ${ }^{145}$

The eligibility date for eligible projects in the national offset system is proposed to be 1 January 2000. The crediting period is proposed to be 1 January 2008, provided there is a government-approved protocol in place for which to earn credits. This means that in order for a project to qualify to earn credits, it must have started after 1 January 2000, and it will begin earning credits from 2008 onwards — there is no credit given for the 2000 to 2008 time period (unlike the Alberta system where crediting can go back to 2002 provided the project meets the eligibility requirements).

The schedule for industry and stakeholders to submit draft quantification protocols for the national offset system will be published (allowing an eight-week window for submissions) according to project type in the summer/fall of 2008. The process will require submitting a letter of intent to develop a quantification protocol.

The federal government will begin its review of project applications for the national offset system in fall 2008. Many details have yet to be worked out and will be revealed in the coming months with the release of the federal "Guidance Documents" for protocols and offsets. However, several of the proposed design features, such as the restricted initial scope, the treatment of biological sinks, and the lack of clarity around start dates and baselines continues to create a lack of certainty for stakeholders under the federal system. Canada, 2008), online: Environment Canada <http://www.ec.gc.ca/doc/virage-corner/2008-03/526_ eng.htm>. 


\section{Potential For Harmonization of Federal and Provincial Systems}

Much more clarity needs to be achieved by the federal government before harmonization of Alberta's and the national offset system can occur. Until design details are firmly nailed down, it will be difficult for policy decision-makers to give certainty to industry and investors. Further, British Columbia and Ontario are moving ahead with regulations that may or may not involve offset credits and harmonization with those systems will need to take place as well. The federal government is in the unenviable position of playing "catch-up" as provinces stride ahead in the design of their emissions trading systems.

The Government of Alberta has consistently issued the message that Alberta has the mandate and will continue to have the mandate to regulate their industries in the province of Alberta. Further statements regarding the harmonization of provincial and federal systems in Alberta press releases and frequently asked questions are:

- $\quad$ building and linking: Alberta will seek to maximize efficiency and resources by building on and linking with existing programs and trading systems;

- $\quad$ Alberta will coordinate with the federal government and continue to work towards a national "one-window" reporting and accounting system;

- $\quad$ it is likely that the CDN\$15 per tonne price cap will go up with time; Alberta will work with the federal government to harmonize; and

- both the federal and Alberta carbon management programs may require some adjustments to be made to the price of carbon. ${ }^{146}$

Given the strong statements from federal Environment Minister John Baird's office that "[Ottawa] welcome[s] all provincial strategies that result in 'real reductions of greenhouse gas emissions, but noted provinces must fall into line with Ottawa’s plan,” and “‘[w]e support any actions that complement our mandatory national emission reductions standards, "' 147 Alberta will likely have some challenges negotiating harmonization since the plans are quite complementary in some respects but very different in others.

Clearly, several questions remain, including the following:

- Will the 2002-2007 offset credits exist in Alberta only? environment.alberta.ca/7.html>; Government of Alberta, Environment, "Frequently Asked Questions,” online: Alberta Environment <http://environment.gov.ab.ca/info/faq.asp>.

147 See Jason Fekete, “Alberta green plan defies federal rules: Environmental groups jeer, oilpatch cheers” Calgary Herald (25 January 2008), online: Calgary Herald <http://www2.canada.com/calgaryherald/ news/story.html?k=60349\&id=97457ce7-95d0-449a-b042-dda002e252a2>, quoting Minister John Baird's senior department official and Garry Keller, director of communications for Baird. 
- How will the 12 percent annual emission intensity target harmonize with the federal government's target of 18 percent in 2010 and 2 percent increase annually thereafter?

- How will Alberta’s \$15 per tonne Technology Fund with unlimited access harmonize with the federal proposal of escalating Technology Fund prices and restricted and diminishing access, until it disappears completely as a compliance option in 2018?

- How will Alberta's treatment of biological sinks harmonize with federal proposals of temporary and permanent offset credits?

- Will Alberta's quantification protocols be recognized in the federal offset system? Will there be common standards to define offset credits across the country?

Unfortunately, until more details are clear, investors, buyers, and project developers will have to wait until more certainty can be provided. However, government insiders report that a spirit of co-operation exists on both sides.

\section{CARbon Emissions Trading Globally — What IS BEING Done?}

Canada has long been active in considering the use of emissions trading mechanisms to confront the challenges of climate change and other environmental issues. ${ }^{148}$ Canada, of course, ratified the Kyoto Protocol ${ }^{149}$ and during the long period between the Kyoto Protocol's negotiation in 1997 and its ratification in 2005, Canadian companies were major participants in voluntary emissions trading, believing as they did in the valuable motto of "learning by doing." Canada's ratification of the Kyoto Protocol and the subsequent coming into force of the Kyoto Protocol led to the federal government moving beyond the initial

A discussion of previous regimes is outside the scope of this article, but readers may wish to consider the Canadian experience with respect to sulphur dioxide $\left(\mathrm{SO}_{2}\right)$ and nitrogen oxides $\left(\mathrm{NO}_{\mathrm{x}}\right)$ trading, and in particular, the following: Convention on Long-range Transboundary Air Pollution, 13 November 1979, 1302 U.N.T.S. 217, 18 I.L.M. 1442 (entered into force 16 March 1983); and the three protocols dealing with $\mathrm{SO}_{2}$ and $\mathrm{NO}_{\mathrm{x}}$ : (1) the 1985 Protocol to the 1979 Convention on Long-range Transboundary Air Pollution on the Reduction of Sulphur Emissions or their Transboundary Fluxes by at least 30 per cent, 8 July 1985, 1480 U.N.T.S. 215, 27 I.L.M. 707 (entered into force 2 September 1987); (2) the 1994 Protocol to the 1979 Convention on Long-range Transboundary Air Pollution on Further Reduction of Sulphur Emissions, 14 June 1994, UN Doc. EB.AIR/R.84, E/ECE/ENHS/ 001/2002/l, 33 I.L.M. 1540 (entered into force 5 August 1998); and (3) the 1988 Protocol to the 1979 Convention on Long-range Transboundary Air Pollution Concerning the Control of Emissions of Nitrogen Oxides or their Transboundary Fluxes, 31 October 1988, 28 I.L.M. 214 (entered into force 14 February 1991). In the U.S., $\mathrm{SO}_{2}$ and $\mathrm{NO}_{\mathrm{x}}$ allowance trading has been used, apparently with great success, in achieving emission reductions beyond targeted reductions at a lower-than-expected cost: see "Acid Rain Program $\mathrm{SO}_{2}$ Allowances Fact Sheet," online: U.S. Environmental Protection Agency <http://www.epa. gov/airmarkets/trading/factsheet.html>. Ontario also has experience with emissions trading in respect of $\mathrm{SO}_{2}$ and $\mathrm{NO}_{\mathrm{x}}$ emissions, see e.g. the Ontario regulation Emissions Trading, O. Reg. 397/01; Ontario Emissions Trading Code, online: Ontario Ministry of the Environment <http://www. ene.gov.on.ca/programs/5295e.pdf >; Ontario Emissions Trading Registry, online: Ontario $<$ http://www.oetr. on.ca/oetr/index.jsp>.

“Kyoto Protocol: Status of Ratification,” online: UNFCCC <http://unfccc.int/files/kyoto_protocol/ status_of_ratification/application/pdf/kp_ratification.pdf>. 
planning and consultation stage (which had prominently featured emissions trading and participation in the Kyoto Protocol mechanisms) to the design of a federal system built around emissions trading and incorporating a number of creative elements. The change in government in Canada in 2006 led to a different approach being taken to climate change, but emissions trading remains central.

GHG regulation has become increasingly prevalent over the past few years and while Canada does not currently actively regulate GHG emissions outside of Alberta and British Columbia, examples of other state, national, and international systems, as well as government proposals, suggest what a Canadian system might look like. At present, and given the growing popular and political will to mitigate climate change, many jurisdictions in North America and internationally appear to be competing with each other to see who can announce the boldest measures. The issue of climate change mitigation is therefore not likely to disappear soon.

\section{A. КYOTO PROTOCOL}

The most famous international document addressing emissions is obviously the Kyoto Protocol and its flexible mechanism, as described earlier in this article, which have resulted in US\$10 billion worth of emissions trading in $2005^{150}$ and US\$25-30 billion in 2006. ${ }^{151}$ As Labatt and White uncontroversially note, the carbon market is already a reality, ${ }^{152}$ but "is still fragmented and struggling for a long-term commitment." ${ }^{153}$ To that end, readers should note the existence of various international regimes and cross-border regional initiatives, some of which have been spurred by the Kyoto Protocol, most notably the EU-ETS, and other international initiatives running parallel (if not counter) to the Kyoto Protocol, namely the Asia-Pacific Partnership on Clean Development and Climate, ${ }^{154}$ and regional initiatives such as the Regional Greenhouse Gas Initiative (RGGI), ${ }^{155}$ the Western Climate Initiative, ${ }^{156}$ and the Midwestern Greenhouse Gas Reduction Accord. ${ }^{157}$

Karen Capoor \& Philippe Ambrosi, State and Trends of the Carbon Market 2006 (May 2006), online: The World Bank Carbon Finance Unit <http://wbcarbonfinance.org/docs/stateoftheCarbonMarket 2006.pdf $>$ at i.

Ibid.

Supra note 20 at 149 .

Ibid. at 167.

Asia-Pacific Partnership on Clean Development and Climate (APP), "Welcome to the Asia-Pacific Partnership on Clean Development and Climate," online: APP <http://www.asiapacificpartnership. org>: the APP is a partnership founded and formed in July 2005 and currently consists of the U.S. (the initiator of the APP), Australia, Canada, China, India, Japan, and Korea. The self-described goal of the APP, which does not favour absolute emissions caps (and therefore, the Kyoto Protocol) and favours technology transfer, is "to work together and with private sector partners to meet goals for energy security, national air pollution reduction, and climate change in ways that promote sustainable economic growth and poverty reduction.”

Online: Regional Greenhouse Gas Initiative <http://www.rggi.org> [RGGI].

Online: Western Climate Initiative <http://www.westernclimateinitiative.org>.

Midwestern Governors Association (MGA), Midwestern Greenhouse Gas Accord 2007, online: MGA $<$ http://www.Midwesterngovernors.org/Publications/Greenhouse\%20gas\%20accord_Layout\%201.pdf>. 


\section{B. INTERNATIONAL EMISSIONS TRADING ASSOCIATION}

The International Emissions Trading Association (IETA) is an independent, non-profit organization dedicated to the establishment of effective systems for trading in GHG emissions by businesses, ${ }^{158}$ which has played a leading role in advocating for market mechanisms to address global warming. The IETA consists of 176 members including various international banks, law firms, companies, consulting firms, and energy companies. The IETA, in conjunction with various other NGOs, launched the Voluntary Carbon Standard in November 2007. ${ }^{159}$ The IETA's leading and influential role in international emissions trading policy makes it an important organization to monitor.

\section{EURopeAn UNION EMISSIONS TRADING SCHEME}

As the European Union (EU) itself stated in 2005, "the EU has developed the largest company-level scheme for trading in emissions of carbon dioxide, making it a world leader in this emerging market." 160 Without a doubt, “[i]t is the EU that has maintained the pace of innovation in carbon markets throughout the painful gestation of the Kyoto Protocol”161 and now the EU-ETS is often referred to as the engine of emissions trading, if not the “centerpiece of Kyoto.”162

The EU, which had signed the Kyoto Protocol as a collective or "bubble," created the EUETS by EU law in 2003. ${ }^{163}$ The EU-ETS is an allowance-based cap-and-trade system designed to achieve the EU's collective Kyoto Protocol obligation (or burden) by allocating the EU's total Kyoto Protocol obligation to each member state. This is done pursuant to a burden-sharing agreement and then allocating "EU Allowance Units" (EAUs) to regulated “installations.” There were approximately 12,000 installations from various industrial sectors, ${ }^{164}$ pursuant to a "National Allocation Plan" (NAP) (subject to the European Commission's approval) within each member state. Each year, each installation is required to surrender EAUs equal to their annual emissions or otherwise pay a fine. Each EU member is required to maintain a national registry to ensure the accurate accounting of the issuance, holding, transfer, and cancellation of allowances. The system also links up with the JI and CDM of the Kyoto Protocol. The EU law also sets out mandatory monitoring and reporting requirements to ensure accurate accounting of allowances and credits.

Online: International Emissions Trading Association (IETA) <http://www.ieta.org/ieta/www/pages/ index.php>.

See Part V.D, below.

European Commission (EC), EU action against Climate Change: EU emissions trading - an open scheme promoting global innovation (Belgium: European Commisssion, 2005), online: EC $<$ http://ec.europa.eu/environment/climate/pdf/emission_trading2_en.pdf >. Labatt \& White, supra note 20 at 143 [citations omitted].

Michael Grubb, "EU ETS and the Future” (Presentation to Point Carbon Conference, 28 February 2006), online: IETA <http://www.ieta.org/ieta/www/pages/getfile.php?docID=1528>.

Directive 2003/87/EC of the European Parliament and of the Council of 13 October 2003 establishing a scheme for greenhouse gas emission allowance trading within the Community and amending Council Directive 96/61/EC, [2003] O.J.L. 275132, online: EUR-Lex <http://eur.lex.europa.eu/LexUriServ.do? uri=CLEX:320030087:EN:NOT>.

Fossil fuel electricity generating facilities, cement facilities, and certain other types of facilities. 
Phase I, which ran from 2005 to 2007 and covered only $\mathrm{CO}_{2}$, was a learning phase marked by various growing pains. Owing to an understandable caution ${ }^{165}$ in respect of free riding competitive activity, the EU membership tended to overstate the number of allowances needed, which upon discovery of that fact, led to a massive depreciation in the price of EAUs from a high of approximately $€ 30$ to a low of $€ 0.10$. Phase II, which is contemporaneous with the first commitment period of the Kyoto Protocol, has been characterized by more stability as the European Commission has taken more control of the process. Phase III (post-2012), which will likely go forward regardless of the Kyoto Protocol, will give the European Commission even greater control over the system: the allocation will take place within the bubble and not based on NAPs and the scheme will likely cover more GHGs and more sectors.

The EU-ETS is important for Canada because of the learning experience it could provide and also because two provinces, British Columbia and Manitoba, have signed co-operation agreements with a number of EU jurisdictions through the International Carbon Action Partnership, ${ }^{166}$ which could lead to linkages in the future. Unlike the proposed regulatory regime proposed for Canada, however, the EU-ETS does not recognize or permit the use of offset credits (credits representing voluntary, additional emission reductions outside of the regulated sector) for compliance purposes.

\section{UNITED STATES}

There has been a flurry of congressional activity related to climate change mitigation efforts. To date, well over 100 bills, resolutions, and amendments have been introduced specifically addressing climate change and GHG emissions. Among the most publicized proposals in this and recent years are those by Senators Joe Liebermann, John McCain, Olympia Snowe, and President Barack Obama, which seek to reduce the GHG emissions of the U.S. in absolute terms to 1990 levels by 2020. The close vote (43 to 55) in 2003 on the McCain-Lieberman Climate Stewardship Act of 2003, ${ }^{167}$ an act which would have set in motion a regulatory process aimed at capping 2010 emissions in various sectors (including electricity generation) at 2000 levels, may also indicate lessening opposition to emissions caps from traditional opponents. Senator Barbara Boxer, now Chair of the Senate Committee on Environment and Public Works, has proposed the same mid-term target, and what appears to be the most ambitious long-term targets to be found among the congressional bills, including a target of 80 percent below 1990 levels by 2050, and unlike the other most publicized congressional proposals, targets for 2030 and 2040 as well. Although the U.S. has not ratified the Kyoto Protocol and is unlikely to do so, ${ }^{168}$ its commitment to the plan for negotiating a new international framework for climate change established at the U.N. Conference on Climate Change in Bali in December 2007 is significant. So too is the fact that each possible candidate of the 2008 presidential election supported emissions caps. This

Danish, supra note 24.

Online: International Carbon Action Partnership <http://www.icapcarbonaction.com/>.

U.S., Bill S. 139, Climate Stewardship Act of 2003, 108th Cong., 2003.

See Danish, supra note 24 at 32: "The United States has opted not to be a party to the Protocol, and the possibility that the United States will join the Protocol before 2012 is increasingly remote irrespective of the party that occupies the Oval Office.” 
suggests a likely shift away from the Bush administration's historical opposition to caps. Furthermore, the results of the November 2008 Senate and House of Representatives elections strengthened the support for caps, in addition to the growing popularity of the issue with the electorate.

In addition to federal initiatives under development, various state and regional initiatives to reduce GHG emissions have also developed in North America. These include the Western Climate Initiative, the Midwestern Greenhouse Gas Reduction Accord, the RGGI in the East, and the leading efforts of the State of California.

\section{CALIFORNIA}

California is taking a role as the climate change leader in the U.S. and is aggressively and influentially pursuing emission reductions with such laws as the California Vehicle Global Warming Law ${ }^{169}$ and the California Global Warming Solutions Act of 2006, ${ }^{170}$ initiatives such as the California Climate Action Registry, ${ }^{171}$ and a renewable energy mandate for certain electricity producers. California is having unparalleled influence on both the GHG emission reduction policies of other states and is being looked upon by several Canadian provinces as a model to follow. What California does with respect to climate change is therefore expected to have a major policy impact in Canada. The State is currently designing a multi-sector cap-and-trade system under the Act. At the end of June 2007, the Market Advisory Committee released its final report and recommendations to the California Air Resources Board (CARB) on the design of a cap-and-trade system. ${ }^{172}$ The major recommendations were that (1) the program should eventually include all major GHG-emitting sectors of the economy; (2) some share of allowances should be allocated free of charge initially, while the remaining allowances should be auctioned, with the percentage of allowances auctioned then increasing over time; (3) offsets generated both within and outside the State's borders should be recognized; and (4) California should encourage linkages with other mandatory cap-and-trade systems. A detailed Californian plan with respect to market-based mechanisms is expected by 1 January 2009. GHG rules and market-based mechanisms are to be adopted by the CARB no later than 1 January 2011 and are to take legal effect by 1 January 2012.

\section{WESTERN CLIMATE INITIATIVE}

Of all the regional initiatives, the Western Climate Initiative is perhaps the most significant. ${ }^{173}$ The Western Climate Initiative, formerly known as the Western Regional Climate Action Initiative, was formed in February 2006 by California, Arizona, New

U.S., A.B. 1493, An act to amend Section 42823 of, and to add Section 43018.5 to, the Health and Safety Code, relating to air quality, 2001-02, Reg. Sess., Cal., 2002.

170 U.S., A.B. 32, An act to add Division 25.5 (commencing with Section 38500) to the Health and Safety Code, relating to air pollution, 2005-06, Reg. Sess., Cal., 2006.

171 Online: California Climate Action Registry <http://www.climateregistry.org/>.

172 The Market Advisory Committee to the California Air Resources Board, Recommendations for Designing a Greenhouse Gas Cap-and-Trade System for California (30 June 2007), online: California Energy Commission <http://www.energy.ca/gov/2007publications/ARB-1000-2007-007/ARB-10002007-007.PDF>. 
Mexico, Oregon, and Washington State. Subsequently, British Columbia joined in April 2007, followed by Utah in May 2007, Manitoba in June 2007, and most recently Ontario on 18 July 2008. Quebec and Saskatchewan are observers, as are several other U.S. and Mexican states. Although the details are still forthcoming, the Western Climate Initiative has established a GHG emission reduction goal of 15 percent below 2005 levels by 2020 as a minimum level to which all members must adhere, and is committed to the establishment of regional market-based mechanisms, such as a cap-and-trade system. Organizers have assigned a committee to consider whether offsets should be included in a market-based mechanism to regulate and reduce emissions of GHGs from within their borders.

\section{REGIONAL GREENHOUSE GAS INITIATIVE}

In the U.S. northeast, several states formed the RGGI ${ }^{174}$ in 2005. The RGGI establishes a cap-and-trade system, but only in respect of electricity, and it deals with only one gas, $\mathrm{CO}_{2}$, although the possibility exists that other GHGs may be covered in the future. The program will cap emissions from covered power plants at current levels in 2009, with reductions of 10 percent required by 2019. The regulated companies would be prohibited from emitting more $\mathrm{CO}_{2}$ from their facilities than they have allowances for, but would be able to use offset credits instead of allowances to demonstrate compliance. A model rule has been promulgated for the states to base their own legislation on. Eleven states have now joined the RGGI and the eastern Canadian provinces have observer status.

\section{New England Governors/EAstern CANAdian PREMIERS Climate Change Action Plan}

In 2001, the New England governors and eastern Canadian premiers developed the Climate Change Action Plan, ${ }^{175}$ a regional initiative with a GHG emission reduction target of 1990 emission levels by 2010 and 10 percent below 1990 levels by 2020. One of the plan's action items is to create a regional emissions registry and explore an emissions trading mechanism.

\section{MIDWESTERN GREENHOUSE GAS ACCORD}

Signed in November 2007, the Midwestern Greenhouse Gas Accord $2007^{176}$ is an agreement between six Midwestern U.S. States and Manitoba as an initiative to develop (1) GHG reduction targets and time frames therefor; (2) a market-based and multi-sector cap-and-trade mechanism; and (3) the necessary tracking, management, and crediting infrastructure. ${ }^{177}$

Supra note 155.

The Committee on the Environment and the Northeast International Committee on Energy of the Conference of New England Governors and Eastern Canadian Premiers, Climate Change Action Plan 2001, online: The New England Governors' Conference, Inc. <http://www.negc.org/documents/NEGECP\% 20CCAP.pdf>.

Supra note 157.

Ibid. at 3. 


\section{E. WHAT CAN CANADA LEARN FROM THE EUROPEAN UNION EXPERIENCE AND THE UNITED STATES MODELS?}

The key lessons from the EU-ETS are that emissions trading regimes are very technocratic institutions that require good design, accurate reporting and monitoring, and a high level of widespread commitment. Fundamental to the genesis of an effective trading system is learning by doing and there should be no doubt that the implementation of GHG emissions trading in Canada will come at the expense of certain difficult lessons. Those lessons, however, must be measured against the opportunity cost of lagging behind other regimes and delaying possible future linkages. "[T]he theory of this [emissions trading] market implies that the bigger the carbon market the lower the overall cost[s] of compliance will be" 178 and there is a strong argument to be made for such linkages. ${ }^{179}$ Therefore, Canada should not lose sight of the experience it will need to acquire in order to achieve effective linkages with other regimes.

\section{THE VOLUNTARY - UnREgUlATED MARKET}

A robust voluntary market for carbon offset credits has been emerging steadily in light of ongoing policy uncertainty in North America, demonstrating that a functional North American GHG reduction and trading system is possible in the absence of federal leadership.

\section{A. PRE-KYoto PROTOCOL EXPERIENCE IN CANADA}

Canada's first major experiences with emissions trading were the Pilot Emission Reduction Trading (PERT) project and the Greenhouse Gas Emission Reduction Trading Pilot (GERT). PERT began in 1996 as an Ontario-based emissions trading project in respect of $\mathrm{NO}_{\mathrm{X}}$ and Voluntary Organic Compounds (VOC) emissions from Ontario power generating stations, but expanded to include carbon monoxide, $\mathrm{SO}_{2}$, and $\mathrm{CO}_{2}$ in 1997. By 1999, approximately 14,000 tonnes of $\mathrm{NO}_{\mathrm{X}}$ reductions and over one million tonnes of $\mathrm{CO}_{2}$ reductions had been registered. ${ }^{180}$ PERT's criteria for emission reduction credits were that the reductions be real, surplus, retrospectively quantifiable, verifiable, and unique. While the market for $\mathrm{NO}_{\mathrm{X}}$ credits eventually faltered due to waning demand, the current Ontario Emissions Trading Registry ${ }^{181}$ maintains an active registry of $\mathrm{NO}_{\mathrm{x}}$ and $\mathrm{SO}_{2}$ allowances for capped emitters, that is, Ontario power generating stations, and emission reduction credits for non-capped entities, such as the Hudson's Bay Company, who then can sell their credits to capped emitters. One example of a trade was in April 2000, when an American power company sold credits representing one million tonnes of $\mathrm{CO}_{2}$ reductions, generated through a landfill methane capture and destruction project, to Ontario Power Generation, which then transferred them to Canada's Climate Change Voluntary Challenge and Registry (acquired by the Canadian Standards Association in January 2005) for retirement. In another trade,

Labatt \& White, supra note 20 at 150-51.

See generally Erik Haites in association with Fiona Mullins, "Linking Domestic and Industry Greenhouse Gas Emission Trading Systems” (October 2001), online: World Business Council for Sustainable Development <http://www.wbcsd.org/web/projects/cement/tf1/IETALinking.pdf>.

"What is PERT and GERT? VCR, ÉcoGESte and the Clean Air Registry?,” online: Environment Canada $<$ http://www.ec.gc.ca/nopp/lfg/primer/en/primer.cfm?pg=5>.

Supra note 148. 
Ontario Hydro bought 35 tonnes of $\mathrm{NO}_{\mathrm{x}}$ emission reduction credits from Shell Chemical, which had claimed the reductions based on an emissions reducing fuel additive.

GERT, launched in June 1998 with a scheduled end of 31 December 2001, was a collaboration between the federal government, nine provinces, and various industry and non-governmental associations, expressly to provide practical experience in the trading of GHG credits in view of the recently signed Kyoto Protocol. In one transaction, Ontario Power Generation purchased approximately 90,000 tonnes of $\mathrm{CO}_{2}$ emission reductions generated by a hydroelectric project which displaced fossil fuel based generation. In another transaction, Pacifica Papers claimed reductions of over 92,000 tonnes of $\mathrm{CO}_{2}$ e per year as a result of replacing three conventional boilers. ${ }^{182}$

\section{B. Voluntary MaRKet GROWTH Since THE Kyoto PROTOCOL}

According to a July 2007 report, "in 2006, 23.7 million tons of carbon dioxide equivalent ... were transacted in the voluntary carbon markets.” 183 Of this, 10.3 million tonnes were transacted on the Chicago Climate Exchange (CCX) while some 13.4 million tonnes were transacted in over-the-counter trades. ${ }^{184}$ It is expected that this market will continue to grow, although the economic recession in the U.S. may affect this expectation.

\section{Chicago Climate Exchange}

The CCX, ${ }^{185}$ which began trading carbon financial instrument contracts representing 100 tonnes of $\mathrm{CO}_{2} \mathrm{e}$ in December 2003, is a private sector entity-based system for voluntary participants, but with the features of a regulatory system. Companies such as Abitibi-Consolidated, Manitoba Hydro, Ford Motor Company, International Paper, IBM, and American Electric Power, and approximately 350 others have listed with the CCX by entering into binding contractual obligations to achieve emission reductions or else purchase them from other members or offset providers ${ }^{186}$ to register with the CCX and whose offsets are verified by a verifier approved by the exchange in accordance with project standards set by the exchange. The CCX includes a registry, entity-level accounting, and independent, third party accounting by the Financial Industry Regulatory Authority (formerly the National Association of Securities Dealers). In Phase I of the CCX (2003-2006), the reduction obligation was 1 percent per year for a total overall reduction of 4 percent against the 2003 baseline. In Phase II (2007-2010), the reduction obligation is 6 percent below the baseline (2003 or 2007, depending on the phase in which the member joins). The CCX is affiliated

Greenhouse Gas Emissions Reduction Training Pilot, News Release, “Greenhouse Gas Trading Pilot Project Announces Completion of First Project Reviews” (16 July 1999), online: Canadian Standards Association, GHG Registries <http://www.ghgregistries.ca/files/projects/prj_5048_642.pdf>.

Ecosystem Marketplace \& New Carbon Finance, State of the Voluntary Carbon Markets 2007: Picking up Steam (17 July 2007), online: Ecosystem Marketplace <http://ecosystemmarketplace.com/ documents/acrobat/StateoftheVoluntaryCarbonMarket17July.pdf $>$ at 5.

Ibid.

Online: Chicago Climate Exchange <http://www.ChicagoClimatex.com>.

Ibid. There are currently eight approved types of projects: agricultural methane, coal mine methane, landfill methane, agricultural soil carbon, rangeland soil carbon management, forestry, renewable energy, and ozone depleting substance destruction. The CCX has stated that it will consider, on a project-by-project basis, energy efficiency and fuel switching projects and CDM-eligible projects. 
with the Montréal Climate Exchange, the European Climate Exchange, and the Chicago Climate Futures Exchange. Climate exchanges are also under development in such jurisdictions as California, New York, ${ }^{187}$ the northeastern U.S., and India.

\section{CORPORATE ACTIVITY}

Leading companies such as Shell Canada Limited, Google, Dell, Home Depot, HSBC, and Wal-Mart Stores have engaged in various initiatives to offset their carbon footprint, either for (1) learning purposes in anticipation of pending regulations; (2) in the hopes of registering reductions for future compliance purposes; and/or (3) as an accountability measure in response to growing demands of customers and investors for accountability on climate change. Entities providing comprehensive support services such as taking inventory of GHG emissions and carbon offsetting service for corporate entities, for example, Morgan Stanley's Carbon Bank (which provides a “carbon zero” certificate once an entity’s carbon footprint is fully offset by qualified credits), are growing in number. ${ }^{188}$

Shell Canada Limited is an example of a business, which uses carbon offsets specifically to reduce its carbon footprint from energy intensive oil sands operations in Western Canada to a level consistent with conventional oil operations. Earlier this decade, Ontario Power Generation acquired emission reduction credits registered with CleanAir Canada from Blue Source LLC, representing up to 6 million metric tonnes of $\mathrm{CO}_{2}$ reductions from American projects, with an option for another 3 million tonnes. ${ }^{189}$

\section{CONSUMERS}

Voluntary carbon credits also fill a steadily growing retail demand on the part of conscientious citizens who wish to offset the emissions from their flights, home energy consumption, transportation, and other activities. To satisfy this growing demand, a diverse range of offset providers such as Zerofootprint, myclimate, the Climate Protection Partnership, and NativeEnergy have emerged, and numerous retailers and consumer service providers, including for example, Air Canada, offer offsets to their customers. As of 31 January 2009, Air Canada's customers have purchased 11,725 tonnes of $\mathrm{CO}_{2}$ offsets for CDN\$187,612 to offset emissions from their flights. ${ }^{190}$

\section{IMPORTANCE OF STANDARDS}

Both regulatory and voluntary systems require certain common elements in order to be able to operate and potentially link to one another in a credible fashion. Without standards,

The New York Mercantile Exchange recently launched trading of credits representing the right to emit one tonne of $\mathrm{CO}_{2}$.

Morgan Stanley, News Release, "Morgan Stanley Announces Creation of Carbon Bank” (14 August 2008), online: Morgan Stanley <http://www.morganstanley.com/about/press/articles/5371.html>.

ClimateBiz, “Case Studies: Blue Source and Ontario Power Generation: Emissions Trade” (2002), online: ClimateBiz <http://www.climatebiz.com/resources/resource/blue-source-and-ontario-powergeneration-emissions-trade>.

Air Canada, “Carbon Offset Program” online: Air Canada <http://www.aircanada.com/en/travelinfo/ traveller/zfp.html>. 
there is a risk of fraud and a risk of frustrating the objectives of voluntary and regulatory climate change initiatives. To that end, a number of private sector and quasi-regulatory bodies have emerged to offer standards in respect of carbon offsets. There are also limits to the public's time and willingness to understand and appreciate the differences between different private sector initiatives. This may lead to their blanket rejection if one or a small number of labels of approval, which businesses and the public are prepared to trust, do not emerge in the near future. Various credible standards do exist, but the increasing flurry of complementary, if not competing standards, has resulted in increased attention from the media and from regulators. In the U.S., for example, the Federal Trade Commission ${ }^{191}$ has been actively considering the need for issuing guidance with respect to carbon offsets. The Australian Competition and Consumer Commission has also announced that it will be scrutinizing environmental claims and claims with respect to offsets, ${ }^{192}$ and it has taken action against companies such as Saab Automobile Australia ${ }^{193}$ for allegedly misleading environmental claims. In Canada, the Competition Bureau and the Canadian Standards Association have released Environmental Claims: A Guide for Industry and Advertisers ${ }^{194}$ with such guidance in respect of environmental claims as: “[a] product from a company that has reduced its greenhouse gas emissions should not claim to be solving the problem of global climate change." ${ }^{195}$ In the United Kingdom, the Department for Environment, Food and Rural Affairs recently released a draft code ${ }^{196}$ of best practices for consumer offsetting products.

\section{VOLUNTARY CARBON STANDARD}

In November 2007, the IETA, The Climate Group, the World Business Council for Sustainable Development, and the World Economic Forum announced that they had completed work on the Voluntary Carbon Standard ${ }^{197}$ (the VCS) with the tag line "quality assurance for the world's carbon market.” The VCS is an international standard for quantification, monitoring, reporting, validation, and verification of offsets for all six of the Kyoto Protocol GHGs, and is essentially the requirements found in the ISO GHG-related

191 Federal Trade Commission (FTC), News Release, "FTC Reviews Environmental Marketing Guides, Announces Public Meetings” (26 November 2007), online: FTC <http://www.ftc.gov/opa/2007/11/ enviro.shtm>.

See the Australian Competition \& Consumer Commission (ACCC), Issues paper, "The Trade Practices Act and carbon offset claims" (16 January 2008), online: ACCC <http://www.accc.gov.au/content/ item.phtml?itemId=808255\&nodeId=7fb158e03286f64038540c9146d08742\&fn=ACCC\%20Issues \%20paper\%E2\%80\%94carbon\%20offset\%20claims.pdf>.

Australian Competition and Consumer Commission, News Release, "ACCC takes action against GM Holden Ltd. over Saab 'green' claims” (18 January 2008), online: ACCC <http://www.accc.gov.au/ content/index/phtml/itemId/808355/fromItemId/810627>.

Canadian Standards Association \& Competition Bureau Canada, Environmental Claims: A Guide for Industry and Advertisers, online: Competition Bureau <http://www.competitionbureau.gc.ca/epic/site/ cb-bc.nsf/en/0270le.html>.

Ibid. at 17.

U.K., Department for Environment, Food and Rural Affairs, Draft Code of Best Practice for Carbon Offset Providers: Accreditation requirements and procedures (18 March 2008), online: Air Transport Users Council <http://www.auc.org.uk/docs/306/Draft\%20Code\%20of\%20Best\%20Practice\%20for\% 20Carbon\%200ffset\%20Providers.pdf>.

Online: Voluntary Carbon Standard <http://www.v-c-s.org/> . 
standards. ${ }^{198}$ Projects must either meet the VCS's methodology (that is, the manner in which a project's baseline is determined and the manner in which GHG reductions or removals are to be estimated), or another methodology, as long as the methodology has been approved by the VCS Association. Projects must be real, measurable, permanent, additional, independently verified, unique, transparent, and conservative. The VCS recognizes the CDM and JI and the Californian Climate Action Registry. Eligible projects receive a Voluntary Carbon Unit (VCU) for each one tonne of $\mathrm{CO}_{2}$ e that has actually been reduced or removed, which can then purportedly be traded. VCUs are to be issued, held and cancelled in VCS registries. No such registries have been created yet and many of the VCS documents are still under development. However, the standard itself, program guidelines, and various guidance documents are currently available.

\section{E. GOLD STANDARD}

In competition with the VCS is the Gold Standard ${ }^{199}$ (GS), which claims to be "the benchmark for quality in the carbon market.” The GS was launched in 2003 by the World Wide Fund for Nature, SouthSouthNorth, and HELIO International, and like the VCS, is a quality assurance label or “credit label” for credits issued for CDM and JI projects and non-Kyoto Protocol voluntary offset projects. Many notable NGOs and business have endorsed, if not used the GS, adding to its perceived credibility. HSBC, for example, has relied on the GS in making its claim to be the world's first major carbon neutral bank, ${ }^{200}$ and the London 2012 Olympic Games ${ }^{201}$ will purchase GS credits to offset all air travel related to the games. To be granted the GS label, projects, which can only relate to renewable energy and energy efficiency projects and not forestry, must undergo third party validation and verification by DOEs pursuant to the Kyoto Protocol mechanisms. Projects must also meet additional requirements relating to stakeholder consultations and satisfaction of three "special screens." ${ }^{202}$ The GS Foundation will then either grant the "GS CER" label for CDM projects or actually issue a "GS Verified Emissions Reductions” credit for voluntary projects. It is unclear what the process is for obtaining the GS label for JI ERUs.

See Part V.F, below.

Gold Standard (GS), The Gold Standard is the benchmark for quality in the carbon market, online: GS <http://www.cdmgoldstandard.org/uploads/file/GS_brochure_07_web2.pdf>.

HSBC, News Release, "HSBC world's first major bank to go carbon neutral” (6 December 2004), online: HSBC <http://www.hsbc.com/1/2/newsroom/news/news-archive-2004/hsbc-worlds-first-majorbank-to-go-carbon-neutral>.

London 2012, News Release, “London pledges to offset carbon emissions” (3 June 2005), online: London $2012<$ http://www.london2012.com/news/archive/bid-phase/london-pledges-to-offset-carbonemissions.php>.

Gold Standard, supra note 199: The GS has three "special screens for quality control” (at 5) in addition to the regular CDM and JI project cycle, which screens are that (1) the project uses renewable energy or energy efficiency techniques; (2) the project goes beyond BAU; and (3) the project promotes sustainable development. The latter two screens, however, appear to be CDM requirements, although the GS Foundation requires that projects satisfy the elements of a qualitative sustainability matrix. The GS Foundation claims that the GS "goes well beyond the CDM guidelines, as it not only tests for additionality but ensures that local stakeholders are involved in the decision making process” (at 6). 


\section{F. INTERNATIONAL ORGANIZATION FOR STANDARDIZATION 14064}

The leading standards with respect to GHG emissions are those offered by the ISO. ${ }^{203}$ The ISO's 14,000-series deals with environmental management standards and the ISO 14064 series in particular deals with standards relating to GHGs. Part 1 is the standard for entity-level description, quantification, and reporting of GHG emissions and removals; Part 2 is the standard for project-level description, quantification, monitoring, and reporting of GHG emission reductions and removal enhancements; and Part 3 is the standard for the validation and verification of GHG assertions. In addition to ISO 14064 is ISO 14065, which is a standard for GHG validation and verification bodies. It is important to note that notwithstanding the growing popularity of ISO 14064, and its endorsement by the UNFCCC, ${ }^{204}$ ISO 14064 and the CDM and/or JI, while comparable, are not the same in application. ${ }^{205}$

\section{G. FUTURE OF VOLUNTARY TRADING}

Voluntary markets have a number of attractive features, including their ability to permit public participation, their ability to motivate activity in areas where regulators fear to go, and their potential to serve as a price safety valve for a regulatory regime (that is, to allow voluntary system credits to be purchased if price of compliance costs rise above a certain threshold). It is suggested that (1) voluntary markets should not be considered as inherently inferior to regulatory approaches; (2) to a great extent, voluntary and regulatory systems can have a complementary relationship; and (3) voluntary markets will continue to flourish regardless of the growth and scope of the regulatory market.

\section{H. WHERE REgUlATED MARKETS Do Not EXIST}

To the extent that there is coherence amongst standards, and to the extent that voluntary systems can seamlessly cross jurisdictional boundaries, they may well offer more universality and lower transaction costs than the large and growing number of state, provincial, and regional efforts currently underway. In regulatory markets of limited size (a salient issue for Canada), voluntary systems may also, more broadly, provide much-needed liquidity. In addition, voluntary systems may provide a source of innovation for regulatory systems. For example, the CCX has found solutions to problems such as the treatment of the risks associated with forestry projects, which have so far frustrated efforts to include sink-based

$203 \quad$ Supra note 115.

204 International Organization for Standardization, News Release, "UNs climate change chief praises new ISO 14064 standards for supporting greenhouse gas reduction and emissions trading” (7 June 2006), online: ISO <http://www.iso.org/iso/pressrelease.htm?refid=Ref1013>.

205 See Stephan Wehr, “CDM and ISO 14064 - Comparability and Ease of Use Review” (Presentation to ISO Seminar on Greenhouse gas quantification, reporting and verification based on ISO 14064 and ISO 14065, 20-21 February 2008), online: South African Bureau of Standards <http://www.sabs.co.za/pdf/ Corporate/1_CDMISO14064Comparison.ppt>: the ISO states that

ISO 14064 requirements are complementary to those of CDM/JI; ISO 14064 requirements are clear and easy to understand, likely streamlining quantification, monitoring and reporting requirements for project developers; additional CDM/JI requirements or guidance can be added for interpretation and application of ISO 14064; UNFCCC participated as observer and endorsed increased use of standardization in this area. 
reductions in rules-based systems internationally and elsewhere (in the CCX, a 20-percent reserve of carbon offsets is held back for forest projects to reflect these risks).

\section{BRIDGING DIFFERING STANDARDS}

Overall, voluntary markets show considerable promise, but at the same time, the growing number of voluntary GHG systems may encounter the same challenges of coherence seen among the diverse approaches of sub-national governments and private groups to climate change. To the extent that broadly accepted national regimes do not emerge, convergence between state, provincial, regional, and voluntary systems, that is, linkages, is arguably very desirable, but voluntary systems may need to coalesce around one or a small number of standards. As explained earlier, a larger market is more desirable from a cost perspective; however, to achieve this larger market, both regulatory and voluntary systems require certain common elements in order to be able to operate and potentially link to one another in a credible and effective manner.

With respect to entity-level mechanisms (for example, the CCX) and project-level mechanisms (for example, the CDM or voluntary offsets), standard methods must be established for establishing the relevant baseline, and for the quantification (sometimes termed accounting or measurement), validation (ex ante) and verification (ex post) of emission reductions, as well as procedures for monitoring and reporting. A credible, well-managed registry and tracking system is necessary in order to show that GHG reductions and any related credits are not being sold or utilized more than once or used for other than their stated purpose. An efficient ownership tracking and trading system will also need services related to the facilitation of transactions, such as clearing, and the standardization of futures contracts, a market-based tool to manage price risk. A leader in this regard, with respect to both mandatory and voluntary GHG emissions trading systems, is the Climate Registry. ${ }^{206}$

\section{CONCLUSION}

Given the widely accepted belief that climate change is a real and imminent global threat for current and future generations, it appears that regulation of GHG emissions will continue to grow provincially, federally, and internationally. As more people become educated about their role in contributing to climate change, they will eventually begin to change their habits and consumption patterns and demand in growing numbers that the companies providing their goods and services do the same. Increased awareness and regulation will both lead to the growth of the voluntary and regulated emissions trading markets. Many analysts and

206 Online: The Climate Registry <http://www.theclimateregistry.org > : the Climate Registry will provide a common entity-wide GHG accounting, reporting, and verification system to support a range of both mandatory and voluntary GHG reduction policies and will allow them to link to one another. Seven Canadian provinces and approximately 40 states, two American-Indian tribal governments, and five Mexican states are currently members. The Climate Registry is not equipped to deal with standards, protocols, and verification tools in respect of project-based mechanisms; however, others such as the Canadian Standards Association are filling the gap through its CleanProjects Registry. This Registry will require all GHG-reduction projects to be validated and verified by an independent third party expert and will employ the internationally recognized carbon accounting standard of ISO 14064. 
emissions trading firms believe that the growth of the voluntary trading market is in its early stages, and that non-regulated emitters such as airlines and consumer product companies have only just begun their green campaigns and initiatives.

It is expected that more consumer goods companies will begin giving consumers an avenue to "carbon-neutral" their purchases.

CCS is expected to be a major factor in assisting industry and nations to meet their GHG reduction targets. Due to its enormous implementation costs, consumers can expect to see their fuel and utility costs begin to reflect the cost of CCS. Governments are emphasizing the development of renewable clean energy technologies and projects and plan to allocate increasing amounts (primarily from climate management funds funded by credit and allowance purchases) to developing and deploying these projects.

One of the exciting by-products of achieving massive GHG reductions will be the reduction in overall air pollution that will be achieved in the process. The world has been successful at achieving reductions of emissions of ozone depleting substances and rebuilding the ozone layer. Scientists hope that industry and government will be successful in cooperating to stabilize climate change and possibly even reverse global warming trends. 